\title{
New amino acid based biodegradable polymers via bis-azlactone chemistry
}

\section{Sophio Kobauri ${ }^{1,2}$, Giuli Otinashvili ${ }^{1}$, Tengiz Kantaria ${ }^{1}$, David Tugushi ${ }^{1}$, Nazibrola Kutsiava $^{2}$, Jordi Puiggali ${ }^{3}$, Ramaz Katsarava ${ }^{1,2^{*}}$}

${ }^{1}$ Institute of Chemistry and Molecular Engineering, Agricultural University of Georgia, $13 \mathrm{~km}$. David Aghmashenebeli Alley, Tbilisi 0131, Georgia;

${ }^{2}$ Centre for Medical Biotechnology and Bioengineering, Georgian Technical University, 77, Kostava str, Tbilisi 0175, Georgia

${ }^{3}$ Barcelona Research Center for Multiscale Science and Engineering. Universitat Politècnica de Catalunya, Escola d'Enginyeria de Barcelona Est-EEBE, c/Eduard Maristany 10-14, Barcelona 08019, SPAIN

Author to whom the correspondence should be addressed; E-mail: r.katsarava@agruni.edu.ge Tel.: +995-32-233-75; Fax: +995-59-915-92-09

Received: / Accepted: / Published:

\begin{abstract}
New biodegradable amino acid based biodegradable (AABB) ester polymers having a potential for constructing resorbable surgical and therapeutical devices were synthesized by solution step-growth polymerization (SGP) of bis-azlactones (BALs) with di-p-toluenesulfonic acid salts of bis-( $\alpha$-amino acid)- $\alpha, \omega$-alkylene diesters (TDADEs). Relatively low-molecularweight homopolymers - poly(ester amide)s with $M_{w}$ within 2,800-19,600 Da (GPC in DMF) were obtained. To increase molecular weights of the goal AABB ester polymers two additional synthetic strategies were applied - either activated diester such as di-p-nitrophenyl sebacate was used as a comonomer of BAL, or alkylene diamine such as 1,6-hexamethylenediamine was used as a comonomer of TDADE. As a result high-molecular-weight AABB ester polymers with $\mathrm{M}_{\mathrm{w}}$ up to 103,500 Da were synthesized depending on co-monomers' structure and mole ratios. All the BAL-based polymers obtained after SGP were practically[1] amorphous. The thermograms (DSC) of the polymers made of the $\mathbf{B A L} \mathbf{L}^{\mathbf{F}}$ showed wide endotherms within $55-120{ }^{\circ} \mathrm{C}$. These endotherms were assigned to melting hydrophobic domains formed by highly hydrophobic fragments - residues of phenylalanine-based bis-azlactone $\left(\mathbf{B A L} \mathbf{L}^{\mathbf{F}}\right)$ in the polymeric backbones. The obtained new BAL-based ester polymers substantially expands a family of AABB polymers destined for constructing resorbable surgical and pharmaceutical devices.
\end{abstract}


Keywords: bis-azlactones, amino acids, bis-diamine-diesters, biodegradable polymers, homopoly(ester amide)s, co-poly(ester amide)s, poly(ester amide-co-amide)s, synthesis, thermal properties, in vitro biodegradation

\section{Introduction}

The synthesis and study of biodegradable polymers is at forefront of modern polymer chemistry because of the technological challenges and a high commercial potential. For many medical, agricultural and environmental purposes it is important to have biodegradable polymers which degrade under the action of physiological environment or in soil "without traces". Materials that can decompose and disappear "without traces" from the body are desirable for a variety of biomedical applications such as surgical and pharmaceutical devices, wound closure/dressing materials, vascular grafts, nerve guidance tubes, absorbable bone plates, orthopedic pins and screws, body-wall/hernia repair, sustained/controlled drug delivery systems, to name a few. Different materials with tailored properties are required for each of these applications. Therefore, biodegradable polymers with a variety of hydrophilicity/hydrophobicity, permeability, morphology, degradation rates, chemical and mechanical properties are needed.

Among a huge variety of biodegradable polymers destined for applications as biodegradable biomaterials, one of the most promising look a relatively new family of the ester polymers on the basis of naturally occurring a-amino acids and other nontoxic building block such as fatty diols and dicarboxylic acids [1-10]. Three main classes of $\underline{\text { Amino }}$ Acid $\underline{B}$ ased Biodegradable (AABB) ester polymers were designed: (i) poly(ester amide)s (PEAs) composed of a-amino acids, fatty diols and dicarboxylic acids, (ii) poly(ester urea)s (PEUs) composed of a-amino acids, one diol and carbonic acid, and (iii) poly(ester urethane)s (PEURs) composed of a-amino acids, one or two diols and carbonic acid.

One of the most promising among AABB ester polymers are PEAs. These polymers combine all advantages of "parent polymers" - aliphatic polyesters and polyamides: ability of biodegradation with a reasonable rate that comes from polyesters, along with a high affinity to and, hence, good compatibility with tissues and a wide range of desired mechanical properties that comes from polyamides. The scopes of applications of AABB PEAs and related polymers can substantially be expanded by their functionalization through the incorporation of various 
groups and sites into the backbones or lateral chains [11-14]. One of the most facile ways to render polymers functional is the incorporation of hydrophobic fragments into the macromolecules [15]. The PEAs with hydrophobic site in the macromolecules can bind various bioactive substances via hydrophobic forces. The existence of hydrophobic sites in the macromolecules can promote their interaction with surfactants that, as a result, can facilitate the preparation of macro- and nanoparticles. Besides, such sites are convenient for surface PEGylation of the beads ${ }^{1}$ by firm hydrophobic anchoring of properly modified PEG molecules [16]. The enhanced hydrophobicity also decreases the stickiness (caused by the plasticizing influence of water) of particulates thus preventing their aggregation. Hydrophobic modification of biodegradable polymers is highly reasonable also for modifying their hydrophobic-hydrophilic balance and, hence, to tune drug release from and biodegradation rates of appropriate polymeric devices.

The present paper deals with the synthesis and study of new hydrophobically modified AABB ester polymers. For the hydrophobic modification of the ester polymers we have selected so called "azlactone method" for the following reasons: (i) starting bis-electrophilic monomers p-phenylene-bis-oxazolinons (bis-azlactones, BALs) are highly active compounds which interact with fatty diamines in organic solvents under mild conditions resulting in high-molecular-weight polyamides (PAs) [17-21], (ii) the reaction is polyadditive, and consequently, after synthesis of the polymer, a low molecular weight by-product is not released, which reduces the impurities in the target polymers, and (iii) the BALs are easily synthesized in high yields by chemical cyclization of corresponding N,N'-terephthaloyl-bis- $\alpha$-amino acids [19,20]. The BALs based PAs [20] are characterized by excellent film-forming properties and biocompatibility, however, their biodegradation rates are too low to be used as biodegradable biomaterials [22]. To render BALs based polymers biodegradable with appropriate rates, easily hydrolysable linkages such as ester linkages have to be incorporated into their backbones - in other words to synthesize PEAs or related ester polymers. For incorporating ester linkages into the polymeric backbones one of the most convenient monomers are amino acid based diamine-diesters [1] - bis-( $\alpha$-amino acid)$\alpha, \omega$-alkylene diesters which are normally used as stable di-p-toluenesulfonic acid salts. These

\footnotetext{
${ }^{1}$ The PEGylation of drug nanocarriers increases their bioavailability. Besides, it helps to overcome the problems connected with the formation of protein "corona", which represents proteins and lipids rapidly adsorbed on their surface when nanosystems are in a physiological environment [17]
} 
salt monomers, referred below as TDADEs, represent key compounds for synthesizing all classes of AABB ester polymers reported previously [1-15].

In the present paper we have used three strategic approaches to the synthesis of three types of new AABB ester polymers made of TDADEs and BALs: 1) the interaction of the TDADEs with the BALs that resulted in homo-poly(ester amide)s (homo-PEAs), 2) the interaction of the TDADEs with a mixture of the BALs and activated diester - di-p-nitrophenyl sebacate (NPS) that resulted in corresponding co-poly(ester amide)s (co-PEAs), and 3) the interaction of a mixture of TDADEs and 1,6-hexanediamine (HDA) with BALs that resulted in corresponding poly(ester amide-co-amide)s (PEA-co-PAs). The elaboration of such synthetic strategy was stipulated by the synthesis of relatively low-molecular-weight homo-PEAs with poor material properties by interaction of BALs (100 mol \%) with TDADEs monomers (100 mol \%) due to the reasons discussed below. Therefore, to increase molecular weights of the goal polymers the basic monomers - BALs and TDADEs were in part replaced by comonomers such as NPS and HDA, accordingly. Copolymers - co-PEAs and PEA-co-PAs were synthesized at mol \% ratios of comonomers: BAL/NPS 50/50, 30/70, 10/90 and TDADEs/HDA 90/10, 50/50, 30/70, 10/90, accordingly.

\section{Experimental part}

\section{Materials and methods}

L-Valine (V), L-leucine (L) and L-phenylalanine (F), 1,6-hexanediol, 12-dodecanediol, 1,6hexanediamine (HDA), terephthaloyl chloride, sebacoyl cloride, p-nitrophenol, p-toluenesulfonic acid monohydrate, acetic acid anhydride, solvents such as acetone, benzene, toluene, ethyl acetate, chloroform, dichloromethane (DCM), pyridine, glacial acetic acid, 1,1,1,3,3,3hexafluoroisopropanol (HFIP), trifluoroethanol (TFE), trifluoroacetic acid (TFA), lithium chloride were purchased from Sigma-Aldrich and used without further purification. Dimethylformamide (DMF), dimetylacetamide (DMA), N-methylpyrrolidone (NMP) and triethylamine (from Sigma-Aldrich) were dried and purified according to standard methods prior to use in the SGP reactions.

The chemical structures of the materials synthesized were characterized by FT-IR and NMR spectra. Thermo Nicolet Avatar 370 FT-IR spectrophotometer (coupled with EZ OMNIC 
software) was used for IR analysis. The FT-IR spectra of the polymers were recorded in thin films cast from HFIP solution directly on an Avatar Multi-Bounce Flat Plate 45 degree Ge. The $300 \mathrm{MHz}{ }^{1} \mathrm{H}-\mathrm{NMR}$ spectra were recorded on a Varian Mercury 300 spectrometer at $303{ }^{\circ} \mathrm{K}$ using DMSO- $d 6 / \mathrm{CCl}_{4}(1: 3 \mathrm{v} / \mathrm{v})$ containing tetramethylsilane (TMS) as an internal standard; the ${ }^{1} \mathrm{H}$ NMR-data was used for the assessment of the co-PEAs composition. The number-average $\left(\mathrm{M}_{\mathrm{n}}\right)$, and weight-average $\left(\mathrm{M}_{\mathrm{w}}\right)$ molecular weights, and molecular weight distribution (Dispersity, $\left.Đ\right)$ of the polymers were determined on a GPC machine (Waters Associates, Inc., Milford, United States. Styragel columns in DMF: HR4, HR3, HR0.5 all $7.8 \mathrm{~mm} \times 300 \mathrm{~mm}$ ) equipped with a high-pressure liquid chromatography pump (Waters 1525 Binary HPLC) and a Waters refractive index detector 2414 and UV-detector (Waters 2487 dual absorbance detector, $\lambda=240 \mathrm{~nm}$ ). A solution of $\mathrm{KBr}(0.1 \mathrm{M})$ in $\mathrm{DMF}$ was used as an eluent. Injected volume $100 \mu \mathrm{L}$, sample concentration $5.0 \mathrm{mg} / \mathrm{mL}$, flow rate $1.0 \mathrm{~mL} / \mathrm{min}$. The columns were calibrated with PMMA standards. In parallel the molecular weight characteristics were measured in HFIP solution using a GPC machine (Shimadzu, model LC-8A) equipped with an Empower computer program (Waters). A PL HFIP gel column (Polymer Lab) and a refractive index detector (Shimadzu RID10A) were employed. The polymer was dissolved in and eluted with HFIP containing $\mathrm{CF}_{3} \mathrm{COONa}(0.05 \mathrm{M}$, to suppress polyelectrolyte effects). Injected volume $100 \mu \mathrm{L}$, sample concentration $2.0 \mathrm{mg} / \mathrm{mL}$, flow rate $0.5 \mathrm{~mL} / \mathrm{min}$. The columns were calibrated with PMMA standards. The thermal properties of new polymers were measured by NETZSCH DSC 200 PC Phox within the temperature range $20-200^{\circ} \mathrm{C}$ under a dry nitrogen gas flow at a heating rate of $10 \circ \mathrm{C} / \mathrm{min}$.

The in vitro biodegradation was studied by both automatic potentiometric titration (APT) [23] and gravimetry (weight loss, WL) [24] using two hydrolases $-\alpha$-chymotrypsin and lipase. Conditions: $\mathrm{pH} 7.4, t=37^{\circ} \mathrm{C}$, enzymes in solution at a concentration $0.4 \mathrm{mg} / \mathrm{mL}$. Substrates: in case of co-PEAs - circular disc-shaped films (cast from $10 \%$ chloroform solutions) of diameter $4.0 \mathrm{~cm}$ and an average weight 400-500 mg, in case of homo-PEAs - $100 \mathrm{mg}$ of the grinded polymer powders sieved through $50 \mu \mathrm{km}$ sieve mesh. In case of the polymeric disc-substrates both APT and WL methods were applied; as far as the hydrophobic polymeric discs were „,noncontractive" they were used without backings recommended in Ref. [23]. In all WL experiments, the film discs were periodically (every $20 \mathrm{~h}$ after the incubation in the enzymes' solution) weighed following to the procedure described in [24] and the weight change per unit surface area 
of the sample was calculated. After each weighing the samples were placed in freshly prepared enzymes' solutions. In case of homo-PEAs' powdery-substrates only APT method was used. In case of APT the biodegradation rate of the polymers was assessed by the quantity of hydrolysed ester bonds (in $\mu$ mole) per minute, which was calculated after 60 min hydrolysis of the polymer as $\mathrm{Q}_{\mathrm{NaOH}} / 60$ where $\mathrm{Q}_{\mathrm{NaOH}}$ is a quantity of $\mathrm{NaOH}$ in $\mu$ mole consumed for neutralizing carboxyl groups released after the hydrolysis of ester bonds. A Metrohm automatic potentiometric titrator 842 Titrando was used in these experiments.

\section{Monomer synthesis}

\section{Bis-electrophilic monomers}

a) Synthesis of the BALs. 2,2'-p-phenylene-bis-(4-isopropyl-oxazolin-5-one) - BAL $\mathbf{L}^{\mathbf{V}}$ and 2,2'-p-phenylene-bis-(4-benzyl-oxazolin-5-one) - $\mathbf{B A L} \mathbf{L}^{\mathbf{F}}$ were synthesized as reported previously [20] by the cyclization of $\mathrm{N}, \mathrm{N}^{\prime}$-terephthaloyl-bis- $\alpha$-amino acids (diamide-diacids, DADAs) as depicted in Scheme 1:
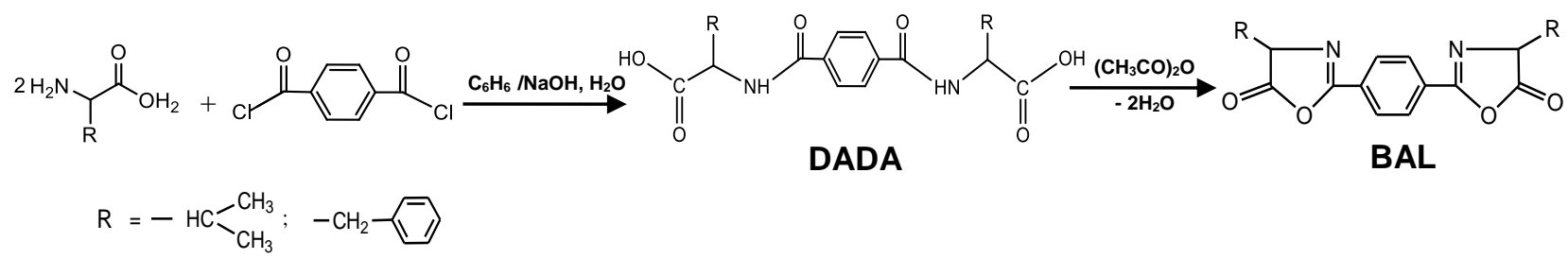

Scheme 1. The synthesis of the BALs.

The intermediate DADAs were synthesized using Shotten-Baumann procedure. The cyclization of the DADAs was carried out in acetic anhydride at $100^{\circ} \mathrm{C}$ [20]. The BALs were recrystallized from benzene. The yield of the $\mathbf{B A L}^{\mathbf{v}}$ was $60 \%$, m.p. $163-164^{\circ} \mathrm{C}$, formula weight $\left(\mathrm{C}_{18} \mathrm{H}_{20} \mathrm{~N}_{2} \mathrm{O}_{4}\right)$ 328.36; The yield of the $\mathbf{B A L} \mathbf{L}^{\mathbf{F}}$ was $80 \%$, m.p. $180-181^{\circ} \mathrm{C}$, formula weight $\left(\mathrm{C}_{26} \mathrm{H}_{20} \mathrm{~N}_{2} \mathrm{O}_{4}\right)$ 424.14. The results well coincide with reported data [20]. As reported previously the BALs are racemic compounds [19,20].

b) Synthesis of the NPS. The synthesis of the activated diester - NPS was carried out as reported previously [25] by the interaction of p-nitrophenol (2.0 mol) with sebacoyl chloride (1.0 mol). The yield of NPS was 89\% (from acetone), m.p. 103-104 ${ }^{\circ} \mathrm{C}$ (reported m.p. 103-104 ${ }^{\circ} \mathrm{C}$ [25]), formula weight $\left(\mathrm{C}_{22} \mathrm{H}_{24} \mathrm{~N}_{2} \mathrm{O}_{8}\right) 444,43$. 


\section{Bis-nucleophilic monomers - TDADEs}

The synthesis of TDADEs was carried out as reported previously [25,26] by direct condensation of an $\alpha$-amino acid with a diol in refluxed toluene, as depicted in scheme 2 :

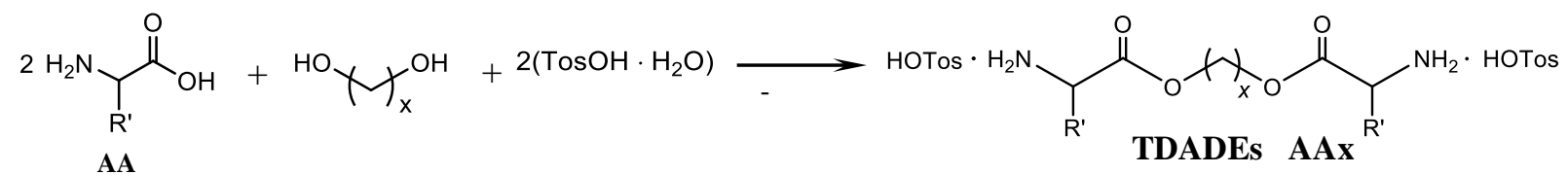

where: $\mathbf{A A}=\mathrm{L}-\boldsymbol{\alpha}$-amino acid $(\mathbf{F}$ or $\mathbf{L}) ; \mathbf{x}=\mathbf{6}, \mathbf{1 2}$. Labelling of the TDADEs AAx: F6, L6, and L12

Scheme 2. The synthesis of the TAADs - F6, L6, and $\mathbf{L 1 2}$.

The yield of the TDADE F6 was 94\%, m.p. $213-215{ }^{\circ} \mathrm{C}$ (reported m.p. $213-215{ }^{\circ} \mathrm{C}[25]$ ), formula weight $\left(\mathrm{C}_{38} \mathrm{H}_{48} \mathrm{~N}_{2} \mathrm{O}_{10} \mathrm{~S}_{2}\right) 756.94$. The yield of the TDADE $\mathbf{L 6}$ was 89\%, m.p. 190-192 ${ }^{\circ} \mathrm{C}$ (reported m.p. 190-192 ${ }^{\circ} \mathrm{C}$ [25]), formula weight $\left(\mathrm{C}_{32} \mathrm{H}_{52} \mathrm{~N}_{2} \mathrm{O}_{10} \mathrm{~S}_{2}\right)$ 688.91. The yield of the TDADE L12 was $88 \%$, m.p. $178-179{ }^{\circ} \mathrm{C}$ (reported m.p. $178-179{ }^{\circ} \mathrm{C}$ [26]), formula weight $\left(\mathrm{C}_{38} \mathrm{H}_{64} \mathrm{~N}_{2} \mathrm{O}_{10} \mathrm{~S}_{2}\right)$ 773.07. The results completely coincide with previously reported data [25,26].

\section{Polymer synthesis}

For synthesizing BAL-based AABB polymers via the SGP we used three strategic approaches: (i) the homo-PEAs were obtained by interaction of the BAL with the TDADE, (ii) the copoly(ester amide)s (co-PEAs) were obtained by interaction of mixtures of the BAL and NPS with the TDADE, and (iii) the poly(ester amide-co-amide)s (PEA-co-PAs) were obtained by interaction of the BAL with mixtures of the TDADE and HDA.

\section{(i) Synthesis of the homo-PEAs via the SGP}

Below are given procedures describing the synthesis of homo-PEA via SGP of the TDADE $\mathbf{L 1 2}$ and BAL $^{\mathbf{v}}$ at variable parameters to establish optimal reaction conditions. At that the following reaction components were invariable: the quantities of $\mathbf{B A L}^{\mathbf{V}}(3.2836 \mathrm{~g}, 0.01 \mathrm{~mol})$ and $\mathbf{L 1 2}$ (7.7307 g, $0.01 \mathrm{~mol}$ ) and the volume ( $2.8 \mathrm{~mL}, 0.02 \mathrm{~mol})$ of TEA. These components were placed in a three-necked $50 \mathrm{~mL}$ round-bottom flask equipped with a stirrer (for the sequence of the components introduction see below); an organic solvent (varying both the nature and volume) was used to carry out the reaction. 
The influence of the order of addition of components. The invariable reaction components above (BAL ${ }^{\mathbf{V}}, \mathbf{L 1 2}$, TEA) and a solvent (DMA) were introduced into the flask in three various sequences:

Sequence "a": (powdery $\mathbf{L 1 2}+$ powdery $\left.\mathbf{B A L}^{\mathbf{V}}\right)$ + (DMA) + (TEA);

Sequence "b": (powdery L12 + TEA) + (powdery BAL $\mathbf{~}$ ) + (DMA);

Sequence "c": (powdery BAL $\mathbf{\text { v }}+$ TEA) + (powdery L12) + (DMA).

The influence of the sequence was studied at the starting temperature $0{ }^{\circ} \mathrm{C}$, monomer concentration 1.2 mole/L $(2.8 \mathrm{~mL}$ of TEA $+5.5 \mathrm{~mL} \mathrm{DMA}=8.3 \mathrm{~mL})$. After adding TEA the reaction mixtures became red in colour that is typical for 4-monosubstituted BALs in the presence of amines $[18,20]$. The reaction mixture was stirred at $0{ }^{\circ} \mathrm{C}$ until its homogenisation and discoloration (1-2 h), then the reaction temperature was increased up to $80{ }^{\circ} \mathrm{C}$ and the solution was stirred again for $18 \mathrm{~h}$. The sequence "a" gave the best results and therefore was applied for the subsequent experiments.

The influence of the solution concentration. To the invariable reaction components above $\left(\mathbf{B A L}^{\mathbf{v}}, \mathbf{L 1 2}\right.$, TEA) a predetermined volume of DMA was added with the purpose to vary a monomer concentration from 0.30 to $1.2 \mathrm{~mole} / \mathrm{L}$ (the volume of TEA $2.8 \mathrm{~mL}$ was taken into consideration). In all cases the starting temperature was $0{ }^{\circ} \mathrm{C}$ and the components were added according to the sequence "a" upon stirring. The reaction mixture was stirred at $0{ }^{\circ} \mathrm{C}$ until its homogenisation and discoloration (1-2 h), then the reaction temperature was increased up to 80 ${ }^{\circ} \mathrm{C}$ and the solution was stirred again for $18 \mathrm{~h}$.

The influence of the starting reaction temperature. In this series of experiments the SGP with participating the invariable reaction components above $\left(\mathbf{B A L}^{\mathbf{v}}, \mathbf{L 1 2}\right.$, TEA) was carried out in DMA at a monomer concentration $1.2 \mathrm{~mole} / \mathrm{L}(2.8 \mathrm{~mL}$ of TEA + 5.5 mL DMA $=8.3 \mathrm{~mL})$ using predetermined starting temperatures such as $0,20,40$ and $80{ }^{\circ} \mathrm{C}$ and the sequence "a". The reaction mixture was stirred at the selected starting temperature until it became homogeneous and colourless (1-2 h) and then the reaction was continued at $80{ }^{\circ} \mathrm{C}$ for $18 \mathrm{~h}$.

The influence of an organic solvent. Three polar aprotic solvents such as DMF, DMA and NMP were examined in the SGP with participating the invariable reaction components above $\left(\mathbf{B A L}^{\mathbf{v}}, \mathbf{L 1 2}, \mathrm{TEA}\right)$ at the following reaction conditions: starting temperature $0{ }^{\circ} \mathrm{C}$ at the sequence "a", solution concentration $1.2 \mathrm{~mole} / \mathrm{L}(2.8 \mathrm{~mL}$ of TEA + $5.5 \mathrm{~mL}$ of an organic solvent $=8.3 \mathrm{~mL}$ ). In case of each of the selected solvents the reaction mixture was stirred at $0{ }^{\circ} \mathrm{C}$ until 
its homogenisation and discoloration (1-2 h), then the reaction temperature was increased up to $80{ }^{\circ} \mathrm{C}$ and the solution was stirred for $18 \mathrm{~h}$.

Optimal reaction conditions. The parameters of the reaction between $\mathbf{B A L}^{\mathbf{V}}$ and $\mathbf{L} 12$ were varied to establish optimal conditions for the SGP of a new type of monomer pair $\mathbf{B A L}+$ salt monomer TDADE. For other BAL-TDADE monomer pairs the SGP was carried out under optimal conditions found: sequence "a", solution concentration 1.2 mole/L, starting reaction temperature $0{ }^{\circ} \mathrm{C}$, solvent DMA, the reaction temperature and duration $80{ }^{\circ} \mathrm{C}$ and $18 \mathrm{~h}$, accordingly. The results are listed in Tab. 1. The parameters which were found as optimal for the monomer pair BAL $\mathbf{V}^{\mathbf{V}}$ / $\mathbf{L 1 2}$ (solution concentration, starting reaction temperature, solvent, the reaction temperature and duration) were applied to the synthesis of all other BAL-based polymers. In some cases, when the gelation of the reaction solutions took place, LiCl was added to homogenize the solutions (see below).

(ii) Synthesis of the co-PEAs

The synthesis of the co-PEAs via SGP was carried out between the BALs, NPS and TDADEs at predetermined mole ratios of BAL/NPS $(0.05 / 0.05,0.03 / 0,07,0.01 / 0.09$, in sum 0.01 mol.). For synthesizing the co-PEAs the following order of addition of components was applied: in a three-necked $50 \mathrm{~mL}$ round-bottom flask equipped with a stirrer, 0.01 moles of a TDADE, $x$ moles of NPS $(x=0.005,0.007$, and 0.009 moles $)$ and $2 x$ moles of TEA were placed, $5.5 \mathrm{~mL}$ of DMA was added and stirred at r.t. until a complete homogenisation of the reaction mixture (1-2 h). Afterwards the reaction solution was chilled to $0{ }^{\circ} \mathrm{C}$ and $(0.01-x)$ moles of a BAL and 2(0.01- $x$ ) moles of TEA were added (in total $2.8 \mathrm{~mL}$ of TEA, TEA + DMA $=2.8$ $+5.5=8.3 \mathrm{~mL}$ that corresponds to the solution concentration of $1.2 \mathrm{~mole} / \mathrm{L}$ ). After adding the BAL, as it was expected, the reaction mixture became red in colour. The reaction mixture was stirred at $0{ }^{\circ} \mathrm{C}$ until its homogenisation and discoloration $(1-2 \mathrm{~h})$, then the reaction temperature was increased up to $80{ }^{\circ} \mathrm{C}$ and the solution was stirred for $18 \mathrm{~h}$. In case when the gelation of the reaction solution was observed, $5 \%$ w/v of $\mathrm{LiCl}$ (calculated per DMA's volume) was added and the reaction was finalized at $80{ }^{\circ} \mathrm{C}$ under the homogeneous condition. The co-PEAs obtained under the said conditions are listed in Tab. 2.

(iii) Synthesis of the PEA-co-PAs

The synthesis of PEA-co-PAs via SGP was carried out between the BALF, TDADE L6 and HDA at predetermined mole ratios of L6/HDA $(0.09 / 0.01,0.05 / 0.05,0.03 / 0.07,0.01 / 0.09$, 
in sum 0.01 mol.). For synthesizing the PEA-co-PAs the following order of addition of components was applied: in a three-necked $50 \mathrm{~mL}$ round-bottom flask equipped with a stirrer, $x$ moles ( $x=0.009,0.005,0.003$, and 0.001 moles) of L6 and (0.01- $x$ ), moles of HAD (as free base) and 0.01 moles of the $\mathbf{B A L} \mathbf{L}^{\mathbf{F}}$ were placed, a precalculated volume of DMA (see below) was added and chilled to $0{ }^{\circ} \mathrm{C}$ upon stirring and then $2 x$ moles of TEA were added. The solution concentration was 1.2 mole/L, i.e. total volume of DMA and TEA was $8.3 \mathrm{~mL}$ as above. Accordingly, the volume of DMA was calculated as $(8.3-2 x \cdot 139.48) \mathrm{mL}$, where $139.48 \mathrm{~mL}$ is the volume of 1.0 mole of TEA. The reaction mixture was stirred at $0{ }^{\circ} \mathrm{C}$ until its homogenisation and discoloration (1-2 h), and then the reaction temperature was increased up to $80{ }^{\circ} \mathrm{C}$ and the solution was stirred for $18 \mathrm{~h}$. In case when the gelation of the reaction solution was observed $5 \%$ w/v of $\mathrm{LiCl}$ (calculated per DMA's volume) was added and the reaction was finalized at $80{ }^{\circ} \mathrm{C}$ under the homogeneous condition (additionally stirred for $1.0 \mathrm{~h}$ ). The PEA-co-PAs obtained under the said conditions are listed in Tab. 3.

\section{Separation of the polymers}

In all cases the reaction solution was filtered and poured into water. The separated polymer was filtered off, thoroughly washed with water, then with ethyl acetate and dried in a vacuum at $60{ }^{\circ} \mathrm{C}$. The yields of the polymers obtained under the optimal reaction conditions were within 8197\% depending on the class and structure (See Tabs. 1-3).

Table 1. Properties of homo-PEAs (GPC data in DMF and HFIP)

\begin{tabular}{|c|c|c|c|c|c|c|c|c|}
\hline \multirow{2}{*}{$\#$} & \multirow{2}{*}{$\begin{array}{l}\text { homo- } \\
\text { PEA* }\end{array}$} & \multirow{2}{*}{$\begin{array}{c}\text { Yield, } \\
\%\end{array}$} & \multicolumn{3}{|c|}{ GPC in DMF } & \multicolumn{3}{|c|}{ GPC in HFIP } \\
\hline & & & Mw & Mn & $\boldsymbol{D}$ & Mw & Mn & $\boldsymbol{\theta}$ \\
\hline$\overline{1}$ & BAL ${ }^{\mathrm{F}}$-F6 & 84 & 2,800 & 2,600 & 1.07 & Incalculable & Incalculable & - \\
\hline 2 & BAL $^{\mathrm{V}}$-F6 & 81 & 10,100 & 6,500 & 1,54 & 5,400 & 1,800 & 3.00 \\
\hline 3 & $B A L^{F}-L 6$ & 85 & 14,000 & 8,400 & 1.67 & 9,900 & 3,300 & 3.00 \\
\hline 4 & BAL $^{\mathrm{V}}$-L6 & 85 & 7,700 & 5,100 & 1,49 & 4,200 & 1,500 & 2.80 \\
\hline 5 & BAL $^{\mathrm{F}}-\mathrm{L12}$ & 92 & 19,600 & 10,400 & 1.88 & 11,700 & 3,100 & 3.77 \\
\hline 6 & BAL $^{\mathrm{V}}$-L12 & 92 & 12,200 & 7,400 & 1.64 & $\mathrm{n} / \mathrm{a}$ & $\mathrm{n} / \mathrm{a}$ & $\mathrm{n} / \mathrm{a}$ \\
\hline
\end{tabular}

${ }^{*}$ For labelling the homo-PEAs see Scheme 4. 
Table 2. Properties of the co-PEAs (GPC data in DMF and HFIP)

\begin{tabular}{|c|c|c|c|c|c|c|c|c|}
\hline \multirow{2}{*}{ \# } & \multirow{2}{*}{ co-PEA* } & \multirow{2}{*}{$\begin{array}{c}\text { Yield, } \\
\%\end{array}$} & \multicolumn{3}{|c|}{ GPC in DMF } & \multicolumn{3}{|c|}{ GPC in HFIP } \\
\hline & & & Mw & Mn & $\boldsymbol{\oplus}$ & Mw & Mn & $\boldsymbol{D}$ \\
\hline 1 & {$\left[\mathrm{BAL}^{\mathrm{F}} / \mathrm{8}\right]_{50 / 50}-\mathrm{F} 6$} & 82 & 35,500 & 18,900 & 1.87 & 16,000 & 6,300 & 2.54 \\
\hline 2 & {$\left[\mathrm{BAL}^{\mathrm{F}} / \mathrm{8}\right]_{30 / 70}$ - F6 } & 85 & 97,500 & 53,600 & 1.82 & $\mathrm{n} / \mathrm{a}$ & $\mathrm{n} / \mathrm{a}$ & $\mathrm{n} / \mathrm{a}$ \\
\hline 3 & {$\left[\mathrm{BAL}^{\mathrm{F}} / 8\right]_{10 / 90}-\mathrm{F} 6$} & 83 & 108,700 & 62,500 & 1.74 & $\mathrm{n} / \mathrm{a}$ & $\mathrm{n} / \mathrm{a}$ & $\mathrm{n} / \mathrm{a}$ \\
\hline 4 & 8-F6 (PEA) & 86 & 78,600 & 41,400 & 1.89 & 25,000 & 10,400 & 2.40 \\
\hline$\overline{5}$ & {$\left[\mathrm{BAL}^{\mathrm{F}} / 8\right]_{50 / 50}-\mathrm{L6}$} & 90 & 61,100 & 36,700 & 1.67 & 26,300 & 11,600 & 2.27 \\
\hline 6 & {$\left[\mathrm{BAL}^{\mathrm{F}} / 8\right]_{30 / 70}-\mathrm{L6}$} & 93 & 62,300 & 36,600 & 1.70 & $\mathrm{n} / \mathrm{a}$ & $\mathrm{n} / \mathrm{a}$ & $\mathrm{n} / \mathrm{a}$ \\
\hline 7 & {$\left[\mathrm{BAL}^{\mathrm{F}} / 8\right]_{10 / 90}$ - L6 } & 92 & $\begin{array}{c}64,300[\mathrm{~J} 2] \\
{[\mathrm{RbD} 3][\mathrm{J4}]}\end{array}$ & 36,000 & 1.78 & 28,000 & 14,200 & 1.97 \\
\hline 8 & 8-L6 (PEA) & 90 & 46,500 & 23,400 & 1.98 & 19,800 & 9,900 & 2.00 \\
\hline 9 & {$\left[\mathrm{BAL}^{\mathrm{F}} / 8\right]_{50 / 50}-\mathrm{L12}$} & 90 & 57,900 & 31,300 & 1.85 & 27,400 & 9,600 & 2.85 \\
\hline 10 & {$\left[\mathrm{BAL}^{\mathrm{F}} / 8\right]_{30 / 70}-\mathrm{L12}$} & 93 & 101,300 & 56,500 & 1.79 & 45,300 & 18,000 & 2.52 \\
\hline 11 & {$\left[\mathrm{BAL}^{\mathrm{F}} / 8\right]_{10 / 90}-\mathrm{L12}$} & 92 & 103,500 & 60,000 & 1.72 & 48,100 & 18,000 & 2.67 \\
\hline 12 & {$\left[\mathrm{BAL}^{\mathrm{V}} / 8\right]_{50 / 50}-\mathrm{L12}$} & 90 & 35,500 & 20,400 & 1.74 & 12,900 & 5,300 & 2.43 \\
\hline 13 & {$\left[\mathrm{BAL}^{\mathrm{V}} / \mathrm{8}\right]_{30 / 70}-\mathrm{L12}$} & 93 & 45,800 & 24,900 & 1.84 & $\mathrm{n} / \mathrm{a}$ & $\mathrm{n} / \mathrm{a}$ & $\mathrm{n} / \mathrm{a}$ \\
\hline 14 & {$\left[\mathrm{BAL}^{\mathrm{V}} / 8\right]_{10 / 90}-\mathrm{L12}$} & 92 & 63,900 & 32,600 & 1.95 & 24,200 & 7,600 & 3.18 \\
\hline 15 & 8-L12 (PEA) & 93 & 76,200 & 42,700 & 1.78 & $\mathrm{n} / \mathrm{a}$ & $\mathrm{n} / \mathrm{a}$ & $\mathrm{n} / \mathrm{a}$ \\
\hline
\end{tabular}

* For labelling the co-PEAs see Scheme 6.

Table 3. Properties of the PEA-co-PAs (GPC data in DMF)

\begin{tabular}{|c|c|c|c|c|c|c|}
\hline \multirow{2}{*}{ \# } & \multirow{2}{*}{ PEA-co-PA* } & \multirow{2}{*}{$\begin{array}{c}\text { Yield, } \\
\%\end{array}$} & \multirow{2}{*}{$\begin{array}{c}\text { Content of } \mathrm{BAL}^{\mathrm{F}} \\
\text { residue, \% } \\
(\Delta \mathrm{H}, \mathrm{J} / \mathrm{g})\end{array}$} & \multicolumn{3}{|c|}{ GPC in DMF } \\
\hline & & & & Mw & Mn & $\boldsymbol{\theta}$ \\
\hline$\overline{1}$ & $\mathrm{BAL}^{\mathrm{F}}$-L6** & 85 & $59.6(28.2)$ & $\overline{14,000}$ & 8,400 & 1.67 \\
\hline 2 & BAL $\left.^{\mathrm{F}}-[\mathrm{L6} / \mathrm{HDA}]\right]_{90 / 10}$ & 94 & $61.4(28.5)$ & 18,800 & 11,400 & 1,65 \\
\hline 3 & BAL ${ }^{\mathrm{F}}-[\mathrm{L6} / \mathrm{HDA}]_{50 / 50}$ & 96 & $70.0(35,7)$ & 45,500 & 27,200 & 1.67 \\
\hline 4 & $\mathbf{B A L}^{\mathrm{F}}-[\mathrm{L6} / \mathrm{HDA}]_{30 / 70}$ & 95 & $75.3(49.7)$ & 65,800 & 37,400 & 1.76 \\
\hline 5 & $\mathrm{BAL}^{\mathrm{F}}-[\mathrm{L6} / \mathrm{HDA}]_{10 / 90}$ & 94 & $81.7(69.3)$ & 89,000 & 49,200 & 1.81 \\
\hline 6 & $\mathbf{B A L}^{\mathrm{F}}-\mathbf{H D A}$ & 97 & $84.8(73.6)$ & 110,400 & 61,300 & 1.80 \\
\hline
\end{tabular}

* For labelling the PEA-co-PAs see Scheme 7.

** Sample \#3 from Tab.1. 


\section{Results and Discussion}

\section{Monomer Synthesis}

Three bis-electrophilic monomers used in the present study for synthesizing the goal polymers were: two bis-azlactones - phenylalanine based 2,2'-p-phenylene-bis-(4-benzyloxazolin-5-on $\left(\mathbf{B A L}^{\mathbf{F}}\right)$ and valine based 2,2'-p-phenylene-bis-(4-isopropyl-oxazolin-5-on $\left(\mathbf{B A L} \mathbf{L}^{\mathbf{V}}\right.$ ) were synthesized according to Scheme 1, as described previously [20], and one activated diester - di-p-nitrophenyl sebacate (NPS) obtained according to Ref. [25]. The characteristics of bis-electrophilic monomers were in full accordance with the reported data [20,25].

Four bis-nucleophilic monomers used in the present study for synthesizing the goal polymers were: three TDADEs - F6, L6 and L12, and one alkylene diamine (free base) HDA. The TDADEs were synthesized according to Scheme 3, as described previously [25,26] and their characteristics were in full accordance with the reported data [25,26]. The HDA was used as free base (as purchased). Labelling of the obtained polymers is given in Schemes 4, 6 and 7 below.

\section{Polymer Synthesis}

\section{(i) Synthesis of the homo-PEAs}

The SGP reaction between BALs and diamines proceeds with opening the azlactone cycle after interaction with amino groups that leads to the formation of two amide links. TDADEs in a salt form (di-tosic acid salt) does not interact with azlactone. To generate the free amino groups from the salt monomer to start the chain growth process, an acid acceptor (e.g. TEA) should be applied (Scheme 4).

The SGP with participating BALs and salt monomers such as TDADEs, depicted in Scheme 4, is a new reaction and we studied its regularities in details. This study comprised the influence of various factors on the molecular weights of the resulted polymers which were assessed by reduced viscosities. First of all we studied the influence of the sequence of the components addition using the monomer pair $\mathbf{B A L}^{\mathbf{v}}$ / L12. We applied three sequences (reduced viscosities of the obtained PEAs are given in parentheses): "a" when to a mixture of powdery TDADE and $\mathbf{B A L}^{\mathbf{v}}$ first was added an organic solvent and then TEA $\left(\eta_{\text {red. }}=0.38 \mathrm{dL} / \mathrm{g}\right)$; "b" 
when to a powdery TDADE first was added TEA (to pre-liberate free amino groups), stirred for 5 min and then added powdery $\mathbf{B A L}^{\mathbf{v}}$ and DMA $\left(\eta_{\mathrm{red}}=0.35 \mathrm{dL} / \mathrm{g}\right)$; "c" when to a powdery BAL $^{\mathbf{V}}$ first was added TEA, stirred for 5 min and then powdery $\mathbf{L 1 2}$ and DMA were added ( $\eta_{\text {red. }}$ $=0.27 \mathrm{dL} / \mathrm{g})$. In all cases the reaction mixtures $(\mathrm{c}=1.2 \mathrm{~mole} / \mathrm{L})$ started at $0{ }^{\circ} \mathrm{C}$ and stirred at this temperature until they became homogeneous and colourless that means the BAL was completely consumed in the SGP. Afterwards, the reaction temperature was increased up to $80{ }^{\circ} \mathrm{C}$ and continued at this temperature for $18 \mathrm{~h}$ (see Experimental Part) to finalize the chain growth. According to the obtained data (reduced viscosities) the best was found the Sequence "a" which was subsequently applied to all experiments when synthesizing homo-PEAs.

We have also studied the influence of the starting reaction temperature which was varied from 0 to $80{ }^{\circ} \mathrm{C}$. The reaction mixtures $(c=1.2 \mathrm{~mole} / \mathrm{L})$ were stirred at a selected temperatures until it became homogeneous and colourless. Afterwards, the reaction temperature was increased up to $80{ }^{\circ} \mathrm{C}$ and continued at this temperature for $18 \mathrm{~h}$. The used starting temperatures and reduced viscosities of the obtained homo-PEAs were as follows: $0{ }^{\circ} \mathrm{C}-0.38 \mathrm{dL} / \mathrm{g}, 20{ }^{\circ} \mathrm{C}-0.31$ $\mathrm{dL} / \mathrm{g}, 40{ }^{\circ} \mathrm{C}-0.28 \mathrm{dL} / \mathrm{g}, 80{ }^{\circ} \mathrm{C}-0.20 \mathrm{dL} / \mathrm{g}$. Hence, $0{ }^{\circ} \mathrm{C}$ was found as the best starting temperature and, therefore, it was subsequently applied for the synthesis of all classes of the polymers.

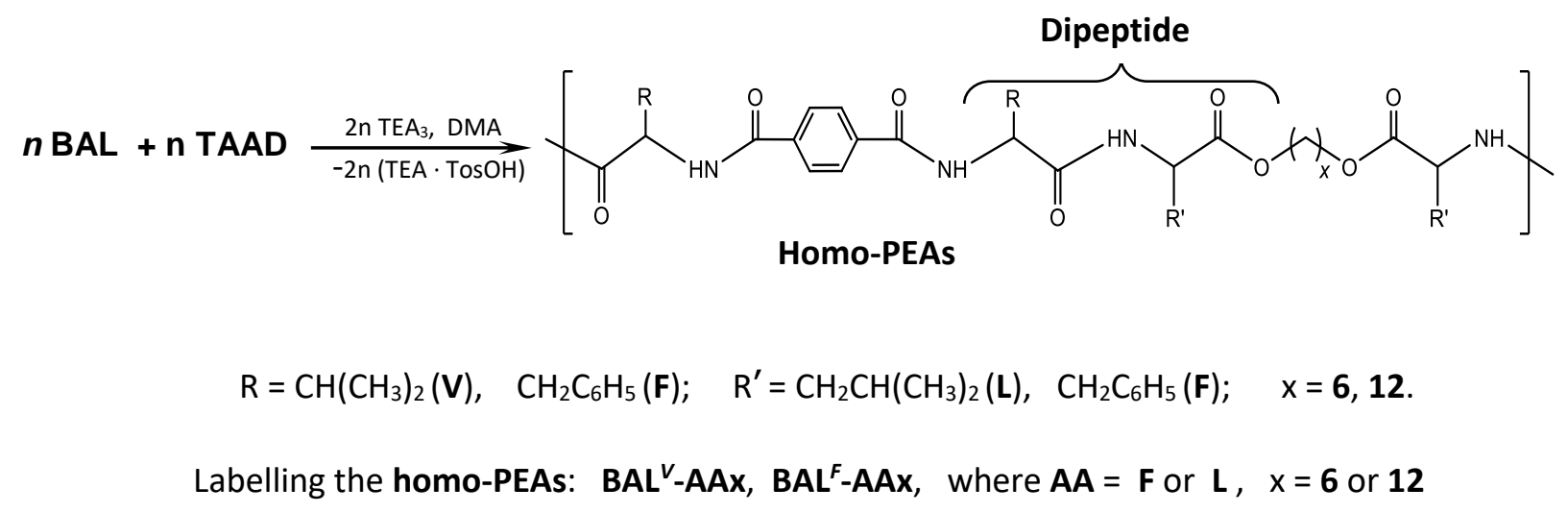

Scheme 4. The synthesis of the BAL-based homo-PEAs

As to the organic solvent very little difference was found between three polar aprotic solvents used, in terms of reduced viscosities of the resulting polymers: DMA $\left(\eta_{\text {red. }}=0.38 \mathrm{dL} / \mathrm{g}\right)$, 
DMF $\left(\eta_{\text {red. }}=0.36 \mathrm{dL} / \mathrm{g}\right)$, and NMP $\left(\eta_{\text {red. }}=0.38 \mathrm{dL} / \mathrm{g}\right)$. Subsequently DMA was used for the synthesis of all classes of the polymers.

From the reaction solutions the polymers were separated by precipitation in water (see Experimental part). The yields and molecular weight characteristics of the homo-PEA obtained on the basis of two BALs - BAL ${ }^{\mathbf{V}}$ and $\mathbf{B A L}^{\mathbf{F}}$ and three TDADEs F6, L6, and L12 according to Scheme 4, are listed in Tab.1. The yields of the homo-PEAs were rather good - within 81-92\%. The homo-PEAs are relatively low-molecular-weight polymers not revealing film-forming properties. Films made of these polymers were brittle and grindable into fine powders. This property makes them promising as biodegradable matrices for preparing sustained releasing drug loaded powdery formulations, e.g. prolonged acting bactericidal powders which could be promising to treat infected deep wounds and cavities.

One of the reasons of the synthesis of relatively low-molecular-weight homo-PEAs could be a steric hindrance between lateral substituents of amino acids $-R$ in BALs and $R^{\prime}$ in TDADEs; the lowest molecular weight of $\mathbf{B A L}{ }^{\boldsymbol{F}}$-F6 - the strongest steric repulsion between the most bulky benzyl groups of BAL ${ }^{\boldsymbol{F}}$ and F6 - could speak for this assumption. However, we assume that one of the main reasons could be a side reaction - TEA-catalysed dimerization of bis-azlactones [18], depicted in Scheme 5. This reaction leads to breaking equimolar ratio of electrophilic/nucleophilic functional groups that, in turn, leads to the restriction of chaingrowth (i.e. decreasing molecular weight) in SGP.

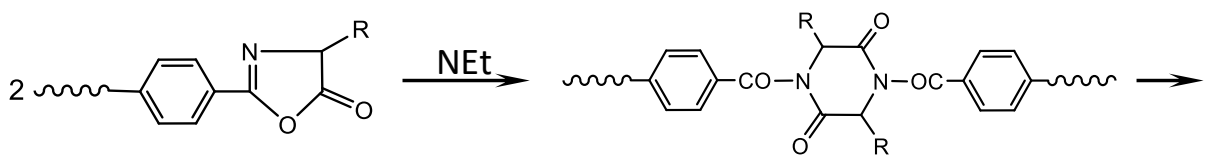

Scheme 5. One of the possible side reactions of azlactone cycle catalysed by tertiary amine.

To decrease the contribution of the side reactions in the SGP with the participation of BALs and TDADEs, we decided to dilute the BAL or TDADE with other monomers. In other words, to replace a part of BAL with NPS or a part of TDADE (salt monomer) by HAD (free base). The reason of these replacements was as follows: (a) p-Nitrophenyl esters of carboxylic 
acids are less prone to side reactions with tertiary amines in polar aprotic solvents [27] and led to high-molecular-weight PEAs after the SGP in DMA in the presence of TEA [25,26]; we assumed, that diminishing the BAL's mole-portion in the SGP by substituting with corresponding mole-equivalent of NPS will decrease the contribution of possible side reactions, e.g. depicted in Fig. 5. (b) The contribution of possible side reactions can also be decreased by replacing a part of a salt monomer - TDADE with a free base - HDA and, hence, by diminishing the quantity of an acid acceptor (TEA). Accordingly, we have synthesized co-PEAs and PEAco-PAs which are discussed below.

\section{(ii) Synthesis of the co-PEAs}

The co-PEAs were synthesized as depicted in Scheme 6. According to this approach, at the initial stage of SGP a predetermined part - 0.50, 0.70, or 0.90 mole/equivalent of the NPS and, accordingly, $1.00,1.40$, or 1.80 mole/equivalents of TEA were added to the 1.00 mole/equivalent of the TDADE monomers - F6, L6, or L12. This means that actually corresponding quantity 0.50, 0.70, or 0.90 mole/equivalents of the initial 1.00 mole/equivalent of the TDADE were interacted with the NPS. The initial stage was carried out at r.t upon stirring until the homogenisation of the reaction mixture (1-2 h). Afterwards, the obtained solution was chilled to $0{ }^{\circ} \mathrm{C}$ and $0.50,0.30$, or 0.10 mole/equivalents of the second bis-electrophilic monomer - either $\mathbf{B A L}^{\mathbf{V}}$ or $\mathbf{B A L}^{\mathbf{F}}$, and additional 1.00, 0.60, or 0.20 mole/equivalents of TEA (in total 2.0 mole/equivalents of TEA per one mole/equivalent of the TDADE) were added. The reaction mixture was stirred at $0{ }^{\circ} \mathrm{C}$ until homogenization, and discoloration of the reaction mixture (1-2 h) that means BAL was completely consumed in the SGP reaction. Then the reaction temperature was increased up to $80{ }^{\circ} \mathrm{C}$ and the solution was stirred for $18 \mathrm{~h}$ to finalize the chain growth.

From the reaction solutions the polymers were separated by precipitation in water (see Experimental part). The yields and molecular weight characteristics of the obtained co-PEA are listed in Tab.2. The co-PEAs were obtained in good yields ranged from 82 to 93\%. The substitution of $50 \mathrm{~mol} \%$ of the BAL by NPS drastically increased the molecular weights (MWs) of the polymers (cf. the following samples: \#1 in Tab.1 and \#1 in Tab. 2, \#3 in Tab. 1 and \#5 in Tab.2, \#5 in Tab.1 and \#9 in Tab.2, and \#6 in Tab.1 and \#12 in Tab.2). As it was expected, the increase of mole portion of NPS up to 70 and 90 mol.\% led to further increase of the MWs of the co-PEAs. Most of the co-PEAs listed in Tab.2 showed excellent film-forming properties. 
$k \cdot n$ BAL $+\boldsymbol{l} \cdot n$ NPS $+n$ TAAD $\frac{2 n \text { TEA }_{3} \text {, DMA }}{-2 n\left(\mathrm{TEA}^{\mathrm{T}} \mathrm{ToSOH}\right)}$

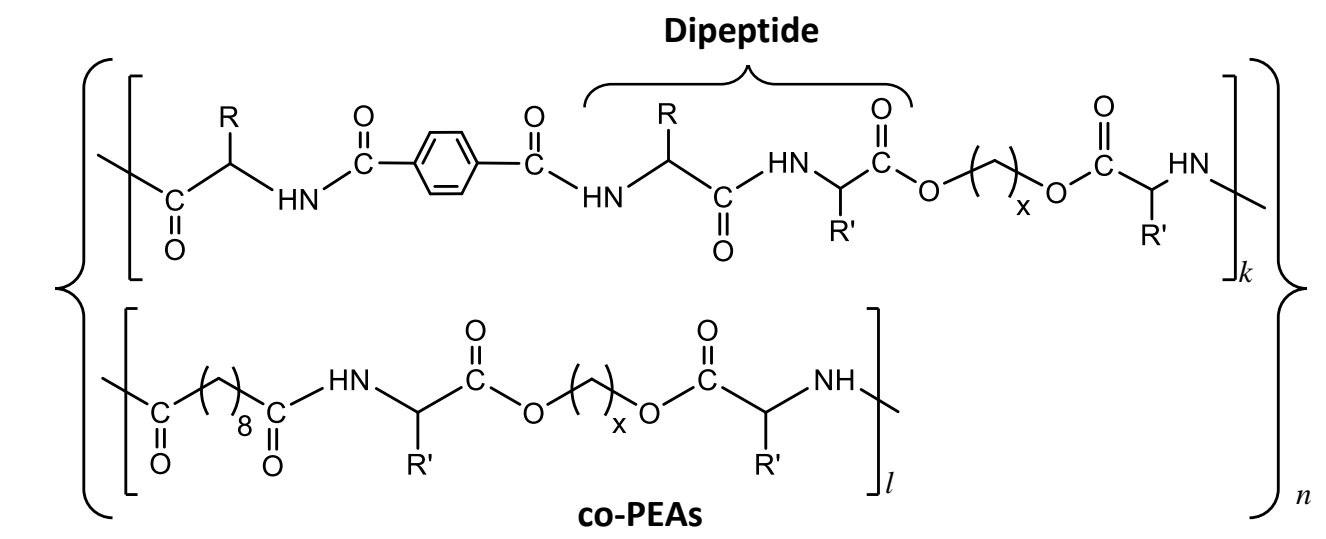

$\mathrm{R}=\mathrm{CH}\left(\mathrm{CH}_{3}\right)_{2}(\mathbf{V}), \quad \mathrm{CH}_{2} \mathrm{C}_{6} \mathrm{H}_{5}(\mathbf{F}) ; \quad \mathrm{R}^{\prime}=\mathrm{CH}_{2} \mathrm{CH}\left(\mathrm{CH}_{3}\right)_{2}(\mathrm{~L}), \mathrm{CH}_{2} \mathrm{C}_{6} \mathrm{H}_{5}(\mathbf{F}) ; \quad \mathrm{x}=\mathbf{6}$ or 12.

Labelling the polymers:

$\left[\mathrm{BAL}^{F} / 8\right]_{k / l}-\mathrm{AAx},\left[\mathrm{BAL}^{F} / 8\right]_{k / l} \mathrm{AAx},\left[\mathrm{BAL}^{V} / 8\right]_{k / l} \mathrm{AAx}$, where $\mathrm{AA}=\mathrm{F}$ or $\mathrm{L}, \mathrm{x}=6,12$. 8 means NPS. $k+l=1 ; \quad k / I=0.5 / 0.5,0.3 / 0.7,0.1 / 0.9$ for co-PEAs, and $0.0 / 1.0$ for PEAs 8-AAx.

Scheme 6. The synthesis of the BAL-based co-PEAs

It has to be noted here that some co-PEAs, especially obtained at a mole ratios $\mathbf{B A L}{ }^{\mathbf{F}} / \mathbf{N P S}$ $=30 / 70$ and 10/90 (when the contribution of chain termination side reactions during the co-PEAs synthesis is minimal), showed higher values of the observed MWs compared to PEAs obtained on the basis of less tend to side reactions NPS only ( $c f$. the following samples listed in Tab.2: \#\# 2 and 3 with \#4, \#\# 5, 6 and \#7 with \#8, \#\# 10 and 11 with \#15). This could be ascribed to higher chain rigidity caused by the bulky and rigid residues of $\mathbf{B A L} \mathbf{F}^{\mathbf{F}}$ (see Fig. 4 below) in the $\mathbf{B A L}^{\mathbf{F}}$ based co-PEAs (which absents in the PEAs 8-AAx) that presumably increases the excluded volume of the BAL $\mathbf{F}^{\mathbf{F}}$-based polymers ( $c f$. the GPC data with DSC data below). For this assumption could speak lack of such kind of correlation in $\mathbf{B A L} \mathbf{L}^{\mathbf{v}}$-based co-PEAs containing less bulky residues of $\mathbf{B A L}^{\mathbf{v}}$ (samples \#\# 12-15 in Tab. 2).

(iii) Synthesis of the PEA-co-PAs 
The PEA-co-PAs were synthesized as depicted in Scheme 7. According to this approach, a predetermined quantity $-0.90,0.70,0.50$, or 0.10 mole/equivalent of the salt monomer TDADE (L6) and $0.10,0.30,0.50$, or 0.90 mole/equivalent of free-base monomer HDA (in sum $\mathbf{L 6}+\mathbf{H A D}=1.00$ mole/ equivalent) was interacted with 1.00 mole/equivalent of the $\mathbf{B A L} \mathbf{L}^{\mathbf{F}}$. For this, to a mixture of the dry monomers a precalculated volume of DMA was added, chilled to 0 ${ }^{\circ} \mathrm{C}$ upon stirring and a precalculated volume of $0.18,0.14,0.10$, or 0.20 mole/equivalent of TEA were added (the volumes of DMA and TEA were calculated so that to keep the solution concentration 1.2 mole.L; the TEA was used in quantities 2.0 mole/equivalent per 1.00 mole/equivalent of TDADE). The subsequent reaction conditions were as above. The stirring at $0{ }^{\circ} \mathrm{C}$ was continued until the homogenisation and discoloration of the reaction mixture (1-2 $\mathrm{h}$ ) that means BAL monomer was completely consumed. Afterwards, the reaction temperature was increased up to $80{ }^{\circ} \mathrm{C}$ and the solution was stirred for $18 \mathrm{~h}$ to finalize the chain growth. If the gelation of the reaction solution was observed, $5 \% \mathrm{w} / \mathrm{v}$ of $\mathrm{LiCl}$ (calculated per volume of DMA) was added and the reaction was finalized by an additional stirring $(1.0 \mathrm{~h})$ under the homogeneous conditions.

$$
n \mathrm{BAL}^{\mathrm{F}}+k \cdot n \mathrm{L6}+\operatorname{l} n \mathrm{HDA} \underset{2 \ln \left(\mathrm{NEt}_{3} \cdot \mathrm{TosOH}\right)}{\stackrel{2 \ln \mathrm{NEt}_{3}, \text { in DMA }}{\longrightarrow}}
$$

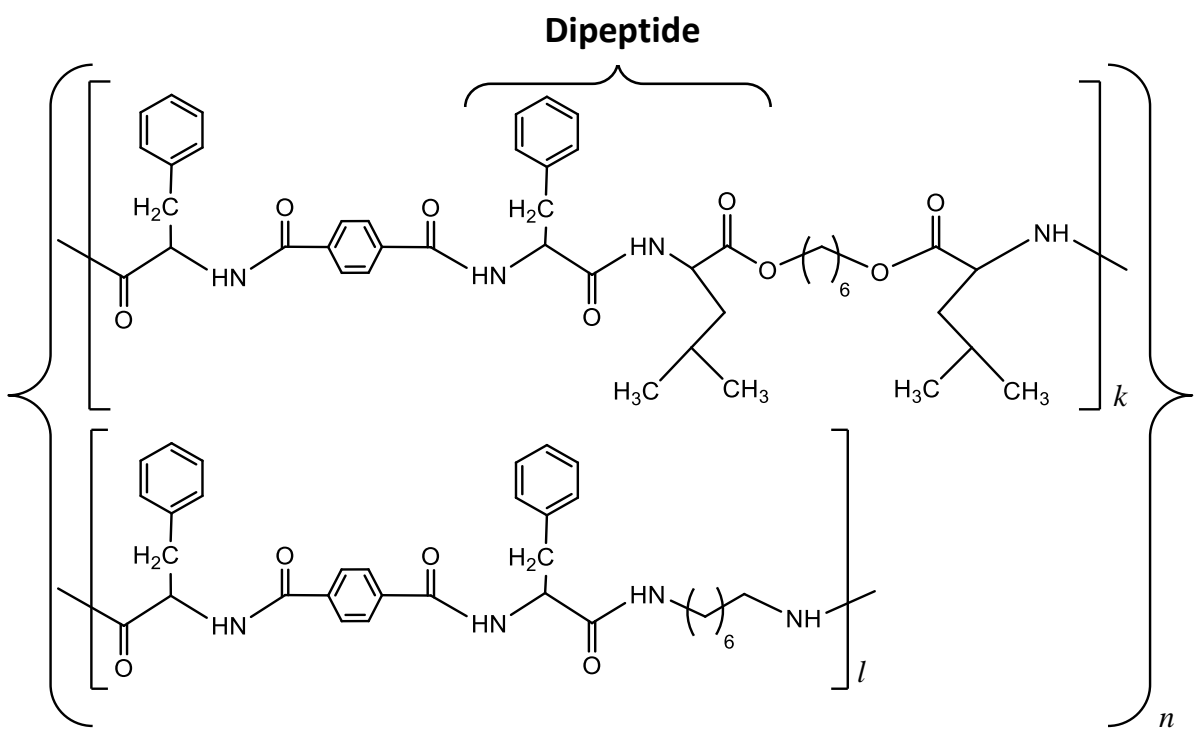

Labelling the polymers: BAL $^{\mathrm{F}}-[\mathrm{L}-6 / \mathrm{HDA}]_{k / l} ; k / /=0.9 / 0.1,0.5 / 0.5,0.3 / 0.7$ and $0.1 / 0.9$ for co-PEAs, and 0.0/1.0 for homo-PEAs 8-AA-x. $k+l=1$;

Scheme 7. The synthesis of the copolymers - PEA-co-PAs 
From the reaction solutions the polymers were separated by precipitation in water (see Experimental part). The yields and molecular weight characteristics of the obtained PEA-co-PAs are listed in Tab. 3. The PEA-co-PAs were obtained in good yields ranged from 85 to $96 \%$. The substitution of $50 \mathrm{~mol} \%$ of the L6 by HDA significantly increased molecular weights of the polymer ( $c f$. the samples \#3 in Tab.1 and \#2 in Tab. 3). As it was expected, the increase of mole portion of HDA up to 70 and $90 \mathrm{~mol} \%$ led to further increase of the MWs of the PEA-co-PAs. All the PEA-co-PAs, containing $\geq 50$ mol.\% of HDA, showed excellent film-forming properties.

\section{Solubility of the polymers}

The solubility of the obtained polymers $(10.0 \mathrm{mg})$ in organic solvents $(1.0 \mathrm{~mL})$ was evaluated (Tab. 4). All of the obtained BAL-based polymers were well-soluble in acidic solvents such as trifluoroacetic acid (TFA) and 1,1,2,2-tetrachloroethane:phenol (3:1 w/w) mixture. Some of them were soluble in chloroform and trifluoroethanol (TFE), and very few - in ethanol

Table 4. Solubility of the polymers in organic solvents

\begin{tabular}{|c|c|c|c|c|c|c|c|c|}
\hline \multirow[b]{2}{*}{ \# } & \multirow{2}{*}{$\begin{array}{l}\text { Polymer } \\
\text { Homo-PEAs }\end{array}$} & \multicolumn{7}{|c|}{ Solubility of $10 \mathrm{mg}$ polymer in $10 \mathrm{~mL}$ solvent at room temperature $\left(25^{\circ} \mathrm{C}\right)$} \\
\hline & & $\begin{array}{c}\mathrm{CHCl}_{3} \\
\text { or } \\
\mathrm{DCM}\end{array}$ & TFE & DMF & EtAc & EtOH & TFA & TCE/PhOH* \\
\hline 1 & BAL ${ }^{\mathrm{F}}-\mathrm{F} 6$ & - & $+\mathrm{t}$ & + & - & - & + & + \\
\hline 2 & BAL ${ }^{\mathbf{V}}$-F6 & Swells & $+\mathrm{t}$ & + & - & - & + & + \\
\hline 3 & $\mathrm{BAL}^{\mathrm{F}}$-L6 & - & + & + & - & - & + & + \\
\hline 4 & BAL ${ }^{\mathrm{V}}-\mathrm{L6}$ & Swells & $+\mathrm{t}$ & + & - & $+\mathrm{t}$ & + & + \\
\hline 5 & BAL $^{\mathrm{F}}$-L12 & - & - & + & - & - & + & + \\
\hline \multirow[t]{2}{*}{6} & BAL $^{\mathrm{V}}-\mathrm{L12}$ & Swells & $+\mathrm{t}$ & + & - & $+\mathrm{t}$ & + & + \\
\hline & Co-PEAs & & & & & & & \\
\hline 1 & {$\left[\mathrm{BAL}^{\mathrm{F}} / \text { 8] }\right]_{50 / 50}$ - F6 } & - & Swells & + & - & - & + & + \\
\hline 2 & {$\left[\mathrm{BAL}^{\mathrm{F}} / \mathbf{8}\right]_{30 / 70}-\mathrm{F6}$} & - & Swells & + & - & - & + & + \\
\hline 3 & {$\left[\mathrm{BAL}^{\mathrm{F}} / \mathrm{8}\right]_{10 / 90}$ - F6 } & - & - & + & - & - & + & + \\
\hline 4 & 8-F6 (PEA) & + & + & + & - & - & + & + \\
\hline 5 & {$\left[\mathrm{BAL}^{\mathrm{F}} / 8\right]_{50 / 50}$ - L6 } & + & - & + & - & - & + & + \\
\hline 6 & {$\left[\mathrm{BAL}^{\mathrm{F}} / 8\right]_{30 / 70}-\mathbf{L 6}$} & + & - & + & - & $+\mathrm{t}$ & + & + \\
\hline 7 & {$\left[\mathrm{BAL}^{\mathrm{F}} / 8\right]_{10 / 90}$ - L6 } & + & $+\mathrm{t}$ & + & - & $+\mathrm{t}$ & + & + \\
\hline 8 & 8-L6 (PEA) & + & + & + & - & + & + & + \\
\hline 9 & {$\left[\mathrm{BAL}^{\mathrm{F}} / \mathrm{8}\right]_{50 / 50}$ - L12 } & + & \pm & + & - & - & + & + \\
\hline 10 & {$\left[\mathrm{BAL}^{\mathrm{F}} / \mathrm{8}\right]_{30 / 70}$ - L12 } & + & \pm & + & - & - & + & + \\
\hline 11 & {$\left[\mathrm{BAL}^{\mathrm{F}} / 8\right]_{10 / 90}$ - L12 } & + & \pm & + & - & - & + & + \\
\hline 12 & {$\left[\mathrm{BAL}^{\mathrm{V}} / \text { 8 }\right]_{50 / 50}$ - L12 } & + & $+\mathrm{t}$ & + & - & - & + & + \\
\hline 13 & {$\left[\mathrm{BAL}^{\mathrm{V}} / \mathbf{8}\right]_{30 / 70}-\mathbf{L 1 2}$} & + & $+\mathrm{t}$ & + & - & - & + & + \\
\hline
\end{tabular}




\begin{tabular}{|c|c|c|c|c|c|c|c|c|}
\hline 14 & {$\left[\mathrm{BAL}^{\mathrm{V}} / 8\right]_{10 / 90-\mathbf{L} 12}$} & + & $+\mathrm{t}$ & + & - & - & + & + \\
\hline 15 & 8-L12 (PEA) & + & + & + & - & + & + & + \\
\hline & PEA-co-PAs & & & & & & & \\
\hline 1 & BAL $^{\mathrm{F}}-[\text { L6 / HDA }]_{90 / 10}$ & - & $+\mathrm{t}$ & + & - & - & + & + \\
\hline 2 & $\mathbf{B A L}^{\mathrm{F}}-[\mathrm{L6} / \mathrm{HDA}]_{50 / 50}$ & - & $+\mathrm{t}$ & + & - & - & + & + \\
\hline 3 & BAL $^{\mathbf{F}}-[\text { L6 / HDA }]_{30 / 70}$ & - & $+\mathrm{t}$ & + & - & - & + & + \\
\hline 4 & BAL $^{\mathrm{F}}-[\mathrm{L6} / \mathrm{HDA}]_{10 / 90}$ & - & $+\mathrm{t}$ & + & - & - & + & + \\
\hline 5 & BALF- HDA & - & Swells & + & - & - & + & + \\
\hline
\end{tabular}

*3:1 (w:w). $\quad «+»$ soluble., «-» insoluble, «tt» soluble upon heating.

(leucine based ones) in which completely aliphatic analogues such as PEAs 8-L6 and 8-L12 showed good solubility. Decreasing the solubility of the BAL-based polymers could be ascribed to rigid terephthalic acid fragments in the polymeric backbones. It is very important that all the polymers were soluble in DMF that allowed to determined their MWs using GPC. All the polymers were insoluble in ethyl acetate (EtAC) which was used for washing the polymers and removing organic impurities from them.

\section{The polymers structure and composition}

The obtained polymers contain dipeptide fragments (see Schemes 4,6 and 7) - AA1$\mathrm{AA}_{2}$, where $\mathrm{AA}_{1}(\mathrm{~F}$ or $\mathrm{V})$ comes from the $\mathrm{BAL}$ and $\mathrm{AA}_{2}(\mathrm{~F}$ or $\mathrm{L})$ comes from the TDADE. These dipeptide fragments are formed as a result of the chain propagation reactions. The structure of the obtained polymers were confirmed by a good coincidence between calculated and found elemental analysis (not given in this paper) and FTIR data: in the spectra of the obtained BAL-based polymers carbonyl absorption bands at $1740-1742 \mathrm{~cm}^{-1}$ (CO- ester), $1640-1650 \mathrm{~cm}^{-1}$ (-CO- amide), 1190-1195 cm-1 (-O- ether), $3300 \mathrm{~cm}^{-1}$ (-NH- amide) were observed. At the same time in the spectra no absorption band at $1810-1820 \mathrm{~cm}^{-1}$ responsible for azlactones $\mathrm{CO}$ was found that meant a complete consumption of the azlactone cycles during the polymers synthesis (discoloration of the reaction solutions (see experimental part) also witnessed for a complete consumption of the BAL-monomer).

The composition of the BAL-based polymers and their fit with the co-monomers feed ratio was studied for representative samples of BAL/L12 based co-PEAs (samples 12-14 in Tab. 2) using ${ }^{1} \mathrm{H}$ NMR data. The calculation was carried out using integral intensities of the NH protons of the amide bonds of both BAL-L12 and 8-L12 blocks of the copolymers, $\mathrm{CH}$ protons of the 
aromatic ring (terephthalic acid's residues), and $\mathrm{CH}_{3}$ protons of isopropyl group (valine residues). The obtained data listed in Tab. 5 showed satisfactory coincidence between the comonomers feed ratio and calculated compositions of the co-PEAs studied.

Table 5. The composition of the co-PEAs according to the feed ratios of the comonomers BAL/NPS and calculated from the ${ }^{1} \mathrm{H}$ NMR data

\begin{tabular}{|c|c|c|c|}
\hline \multirow{2}{*}{$\#$} & \multirow{2}{*}{ co-PEA } & \multicolumn{2}{|c|}{ The composition of the BAL-L12 and 8-L12 blocks } \\
\cline { 3 - 4 } & & $\begin{array}{c}\text { The feed ratio of } \\
\text { BAL/NPS }\end{array}$ & $\begin{array}{c}\text { Calculated from } \\
\text { data NMR }\end{array}$ \\
\hline 1 & {$\left[\mathrm{BAL}^{\mathrm{V}} / 8\right]_{50 / 50}-\mathrm{L12}$} & $50: 50$ & $48: 52$ \\
\hline 2 & {$\left[\mathrm{BAL}^{\mathrm{V}} / 8\right]_{30 / 70}-\mathrm{L12}$} & $30: 70$ & $29: 71$ \\
\hline 3 & {$\left[\mathrm{BAL}^{\mathrm{V}} / 8\right]_{10 / 90}-\mathrm{L12}$} & $10: 90$ & $12: 88$ \\
\hline
\end{tabular}

\section{Molecular weights of the polymers by GPC}

The molecular weight characteristics of the obtained polymers $-M_{w}, M_{n}$ and $M_{w} / M_{n}$ (Dispersity, $Ð)$ were determined using GPC in two organic solvents - DMF containing $\operatorname{LiBr}(0.1$ $\mathrm{M}$ solution) and HFIP containing $\mathrm{CF}_{3} \mathrm{COONa}$ (0.05 $\mathrm{M}$ solution). The results of these measurements, listed in Tabs. 1-3 show that the MWs determined in DMF are two-three times higher than MWs determined in HFIP. The dispersity $Ð$ measured in DMF $\leq 2.0$ (it is within 1.52.0) that is typical for AABB polymers [1-5] and in general for polymers obtained via SGP. The dispersity $Ð$ measured in HFIP in the most cases $\geq 2.0$ and in some cases even $\geq 3.0$ that are high values for polymers obtained via SGP.

To explain the contradictory data obtained after the GPC measurement in two different solvents, we assume that $\mathrm{LiBr} / \mathrm{DMF}$ is a good solvent and $\mathrm{CF}_{3} \mathrm{COONa} / \mathrm{HFIP}$ is a poor solvent for the obtained macromolecular systems. LiBR/DMF as a good solvent provides high excluded volumes of macromolecules whereas $\mathrm{CF}_{3} \mathrm{COONa} / \mathrm{HFIP}$ causes the shrinkage of the macromolecules to compact globule with lower excluded volumes. It has to be noted that MWs, in spite of the difference in the values, are changed parallelly - the higher is MW in DMF the higher is MW in HFIP, and vice-versa. High values of the dispersity $Đ$ in HFIP could be connected with the formation of compact globules and this compacting does not happen uniformly with constant factor - we assume that for smaller molecules the shrinkage is more 
pronounced. In other words, in GPC measurements decreasing $\mathbf{M}_{n}$ values is more substantial than decreasing $M_{w}$ values that leads to increasing the fraction $M_{w} / M_{n}$, i.e. $Đ$.

\section{Hydrophobicity assessment of the polymers}

The hydrophobicity of the BAL-based polymers was assessed by weight gain of the polymeric films immersed in water. Four co-PEAs on the basis of L12, were selected for this study: $\left[\mathrm{BAL}^{\mathrm{F} / 8}\right]_{30 / 70}-\mathbf{L 1 2},\left[\mathrm{BAL}^{\mathrm{F} / 8}\right]_{10 / 90}-\mathbf{L 1 2},\left[\mathrm{BAL}^{\mathrm{V} / 8}\right]_{30 / 70}-\mathbf{L 1 2}$, and $\left[\mathrm{BAL}^{\mathrm{V} / 8}\right]_{10 / 90}-\mathbf{L 1 2}$; the PEA 8L12 was also used for a comparative study. The obtained results given in Fig.1 reveals that among the polymers studied the PEA 8L12 showed the lowest and the co-PEA $\left[\mathbf{B A L}^{\mathbf{F}} / \mathbf{8}\right]_{\mathbf{3 0} / 70}-\mathbf{L 1 2}$ the highest hydrophilicity. The co-PEAs made of the $\mathbf{B A L}^{\mathbf{F}}$ are more hydrophobic than the co-PEAs made of the $\mathbf{B A L}^{\mathbf{V}}-$ e.g. the co-PEA $\left[\mathrm{BAL}^{\mathrm{F}} / \mathbf{8}\right]_{10 / 90}-\mathbf{L 1 2}$ composed of $10 \mathrm{~mol} \%$ of $\mathbf{B A L} \mathbf{L}^{\mathbf{F}}$ shows almost the same hydrophobicity as the co-PEA $\left[\mathbf{B A L}^{\mathbf{V}} / \mathbf{8}\right]_{30 / 70}$ composed of $30 \mathrm{~mol} \%$ of $\mathbf{B A L}^{\mathbf{v}}$ (cf. curves $\mathbf{c}$ and $\mathbf{d}$ ). This could be ascribed to a higher hydrophobicity of phenylalanine compared to valine: the Hansch hydrophobicity constant of isopropyl group of valine is 1.30 , whereas for benzyl group of phenylalanine it is twice as higher - 2.63 [28].

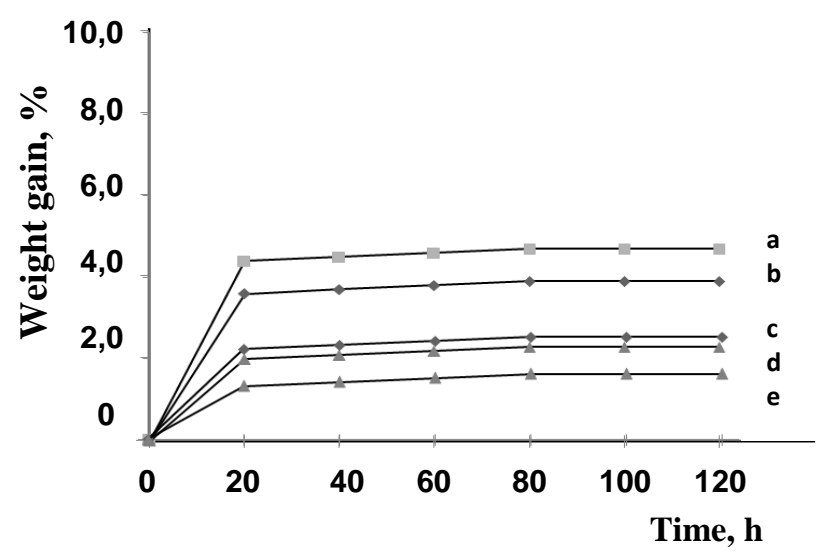

Fig. 1. Water absorption by the polymeric films $\left(37^{\circ} \mathrm{C}\right)$ : The films made of the PEA 8-L12 (a) and coPEAs: $\left[\mathrm{BAL}^{\mathrm{V} / 8}\right]_{10 / 90}-\mathrm{L12}(\mathrm{b}),\left[\mathrm{BAL}^{\mathrm{V}} / 8\right]_{30 / 70}-\mathrm{L12}(\mathrm{c}),\left[\mathrm{BAL}^{\mathrm{F}} / 8\right]_{10 / 90}-\mathrm{L12}(\mathrm{d}),\left[\mathrm{BAL}^{\mathrm{F}} / 8\right]_{30 / 70}-\mathrm{L12}(\mathrm{e})$.

Hence, the hydrophobicity of the polymers can be tuned by varying the structure and content of the BALs in the polymeric backbones. 


\section{Thermal properties}

Thermal properties of the polymers were studied within the temperature range of $20-200$ ${ }^{\circ} \mathrm{C}$. The thermograms showed wide endotherms in the range $55-120{ }^{\circ} \mathrm{C}$ with maximums within 86-96 ${ }^{\circ} \mathbf{C}$ (Figs. 2 and 3). The endotherms were observed in case of all the $\mathbf{B A L} \mathbf{L}^{\mathbf{F}}$-based polymers: homopolymers such as BAL ${ }^{\mathbf{F}}$-L6 and BAL ${ }^{\mathbf{F}}$-HDA (Figs. 2, curves I and II, accordingly), and BAL F-F6 (Fig. 3, curve I), as well as in case of corresponding copolymers - PEA-co-PAs (Figs. 2, curves III-VI) and co-PEAs (Fig. 3, curves II and III). This wide endotherm was not observed in the thermogram of 8-F6 (Fig. 3, curve IV) which represents a fatty PEA free of rigid aromatic residues in the backbones - a sharp endothermal peak, which corresponds to melting crystalline phase, was observed instead at $106^{\circ} \mathrm{C}$ (reported m.p. of the PEA 8-F6 $108{ }^{\circ} \mathrm{C}$ [25]).
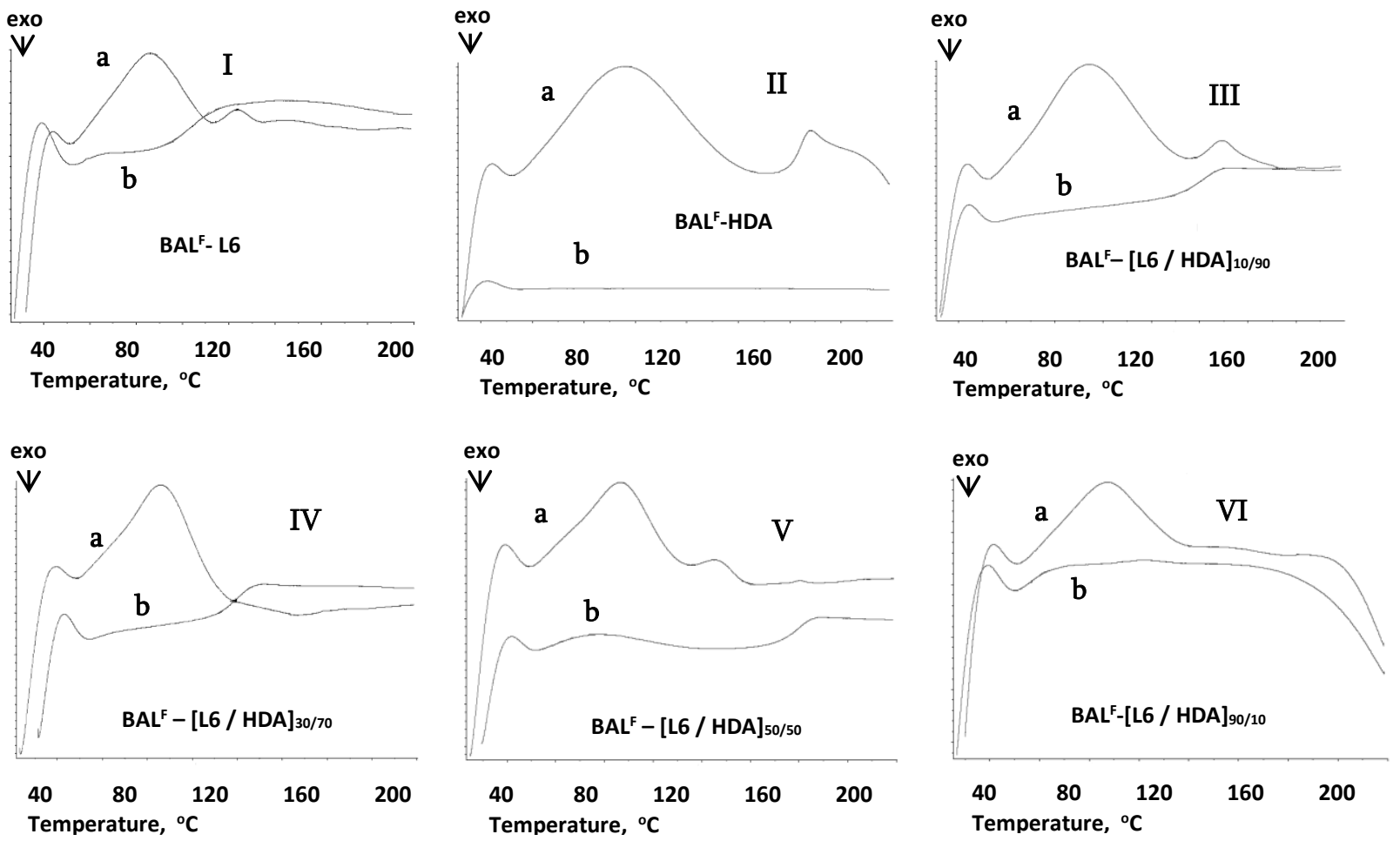

Fig.2. The thermograms of the BAL ${ }^{\mathbf{F}}$ based homopolymers BAL ${ }^{\mathbf{F}}$-L6 (I) and $\mathbf{B A L} \mathbf{L}^{\mathbf{F}}$-HDA (II), and corresponding copolymers PEA-co-PAs (III-VI); $\mathbf{a}$ - the first scan, $\mathbf{b}$ - the second scan. 
Both the broadened form and low temperature range $\left(55-120^{\circ} \mathrm{C}\right)$ of the endotherms allow to assign them rather to amorphous or [J5]small crystalline domains (involving probably lateral groups) than to crystalline phase[J6]. This assumption is in conformity with our previous finding that all the BAL-based polymers (even relatively more symmetric homo-polyamides such as e.g. BAL $^{\mathbf{F}}$-HDA) according to X-ray analysis are amorphous [20]; this is because of racemic nature of BALs that leads to statistical distribution of $\mathrm{L}$ and $\mathrm{D}$ amino acids' residues which come after the opening the azlactone cycles. Taking into account that these types of endotherms were not observed in case of the $\mathbf{B A L} \mathbf{L}^{\mathbf{V}}$-based polymers

(not given in this paper), we suppose that responsible for these domains are highly hydrophobic fragments - residues of $\mathbf{B} \mathbf{A} \mathbf{L}^{\mathbf{F}}$ in the polymeric backbones (Fig. 4) which are formed as a result of opening the azlactone rings after the reaction of $\mathbf{B A L} \mathbf{L}^{\mathbf{F}}$ with primary amino groups of TDADEs or HAD monomers. The thermograms of the co-PEAs the most likely represent an overlapping the melting of the hydrophobic domains formed by the $\mathbf{B} \mathbf{A L} \mathbf{L}^{\mathbf{F}}$ residues and crystalline phase formed by 8-L6 blocks (see Fig. 3, cf. thermogram II and, especially, thermogram III with thermogram IV).
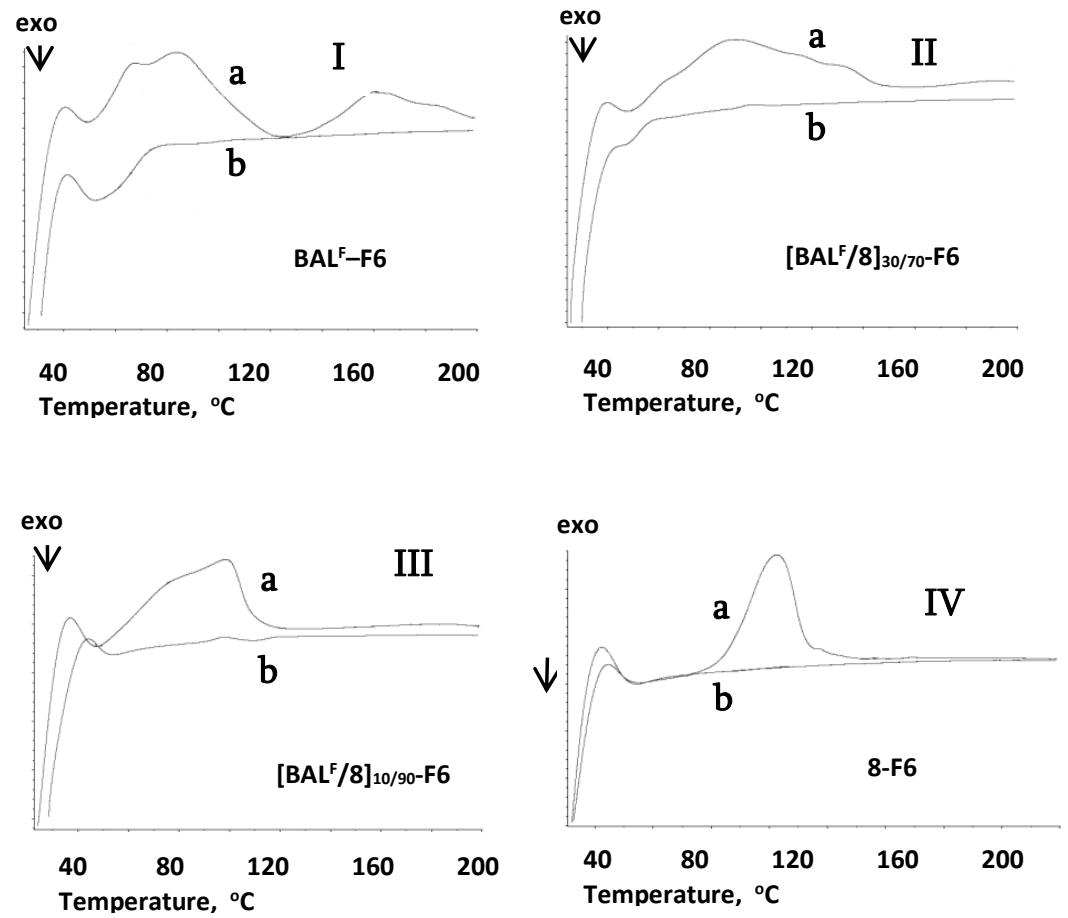

Fig.3. The thermograms of the BAL ${ }^{\mathbf{F}}$ based homo-PEABAL $\mathbf{L}^{\mathbf{F}}-\mathbf{F 6}(\mathbf{I})$ and Corresponding co-PEAs $\left[\mathrm{BAL}^{\mathrm{F}} / \mathbf{8}-\mathbf{F 6}\right]_{\mathbf{3 0 / 7 0}}$ (II) and $\left[\mathrm{BAL}^{\mathrm{F}} / \mathbf{8}-\mathbf{F 6}\right]_{\mathbf{1 0} / \mathbf{9 0}}(\mathrm{III})$, and aliphatic PEA 8-F6 (IV); $\mathbf{a}$ - the first scan, $\mathbf{b}$ - the second scan.

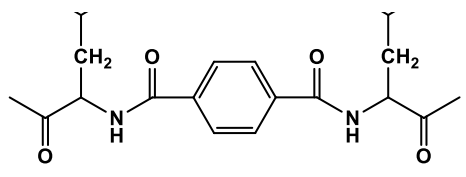


This assumption regarding the melting of the hydrophobic domains rather than the crystalline phase is confirmed by the representation of the melting enthalpy ( $\Delta \mathrm{H}$ in J/g) of the hydrophobic domains in BAL ${ }^{\mathbf{F}}$ based PEA-co-PAs and homopolymers BAL ${ }^{\mathbf{F}}$-L6 and $\mathbf{B A L}^{\mathbf{F}}$ HDA vs. BAL ${ }^{\mathbf{F}}$ residues content in the polymeric backbones (Fig. 5) - the higher is the $\mathbf{B A L}^{\mathbf{F}}$ content the higher is the melting enthalpy of the polymer.

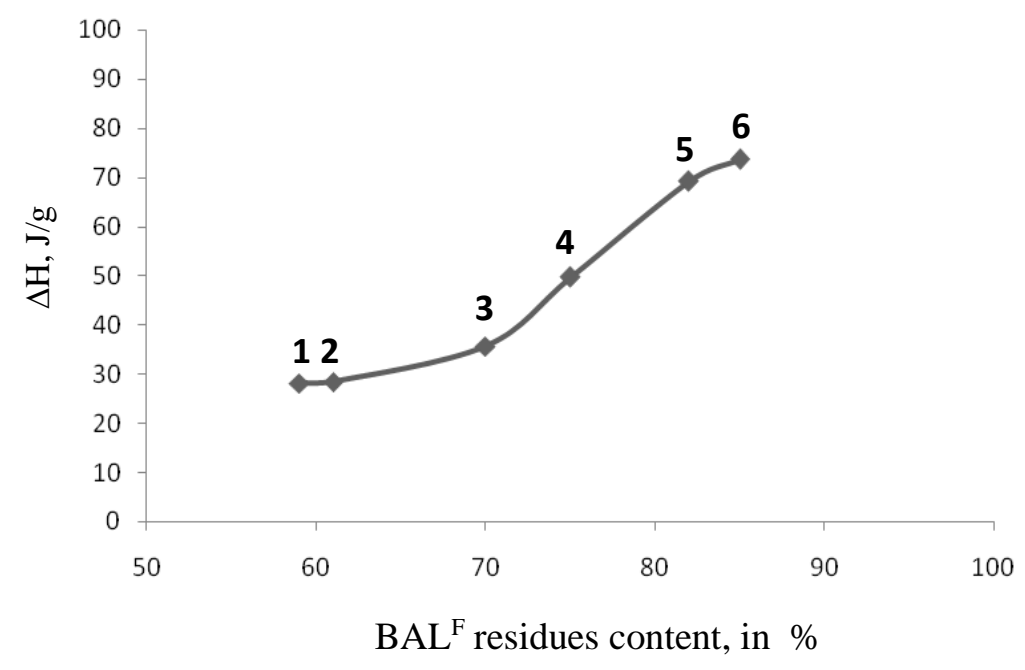

Fig.5. Melting enthalpy ( $\Delta \mathrm{H}$ in $\mathrm{J} / \mathrm{g}$ ) of the hydrophobic domains in $\mathbf{B A L} \mathbf{L}^{\mathrm{F}}$ based PEA-co-PAs (2-5) and homopolymers BAL ${ }^{\mathbf{F}}$-L6 (1) and BAL ${ }^{\mathbf{F}}$-HDA (6) vs. BAL ${ }^{\mathbf{F}}$ residues (see in Fig. 4) content in the polymeric backbones. The figures on the curve correspond to the numbers of the polymer samples in Tab. 3.

It has to be noted here that after melting and cooling (see the second scan in Figs. 2 and 3) the hydrophobic domains were not rebuilt. This behaviour is similar to semi-crystalline AABBB PEAs [25] which also were not recrystallized after melting-cooling cycles - the crystalline phase was rebuilt only after dissolving of the amorphous melt in an organic solvent (e.g. chloroform) and casting as a film and drying.

[J7] 


\section{Biodegradation}

The in vitro biodegradation of films of the selected samples of the obtained polymers (co-PEAs) was studied using both APT (Figs. 6-8) and weight-loss (Fig. 9) methods under the conditions close to

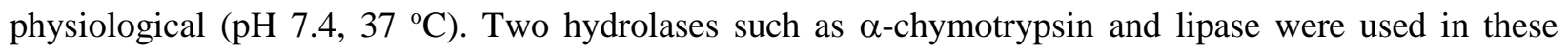
experiments. The potentiometric titration study showed that after incorporating rigid and highly hydrophobic terephthalic acid residues into the polymeric backbones the polymers retained biodegradability, though these polymers showed somewhat lower biodegradation rate as compared with the fully aliphatic analogue 8-L12. The quantity of terephthalic acid residues in both $\mathbf{B A L}^{\mathbf{v}}$ (Fig. 6) and $\mathbf{B A L}^{\mathbf{F}}$ (Fig. 7) polymers influenced the biodegradation rate - the higher was its content in the backbones the lower was the rate ( $c f$. $\mathbf{a}$ and $\mathbf{b}$ in Figs. 6 and 7). The lower biodegradation rate of the co-PEAs on the basis of $\mathbf{B A L}^{\mathbf{F}}$ ( $c f$. date given in Figs. 6 and 7) could be in part ascribed to the formation of the hydrophobic domains above which impede the access of the enzymes to the ester bonds (analogously to crystalline phase in polymers). The study of the homo-PEAs made of $\mathbf{B A L} \mathbf{L}^{\mathbf{v}}$ powders showed that the $\alpha$ chymotrypsin catalyzed biodegradation rate of the polymer on the basis of more hydrophobic F6 is lower than on the basis of less hydrophobic L6 ( $C f$. $\mathbf{a}$ and $\mathbf{b}$ in Fig. 8,A). It has also to be noted that the enzyme ( $\alpha$-chymotrypsin) catalysed hydrolysis was much faster compared to nonspecific (chemical) hydrolysis (Cf. b and $\mathbf{c}$ in Fig. 8).
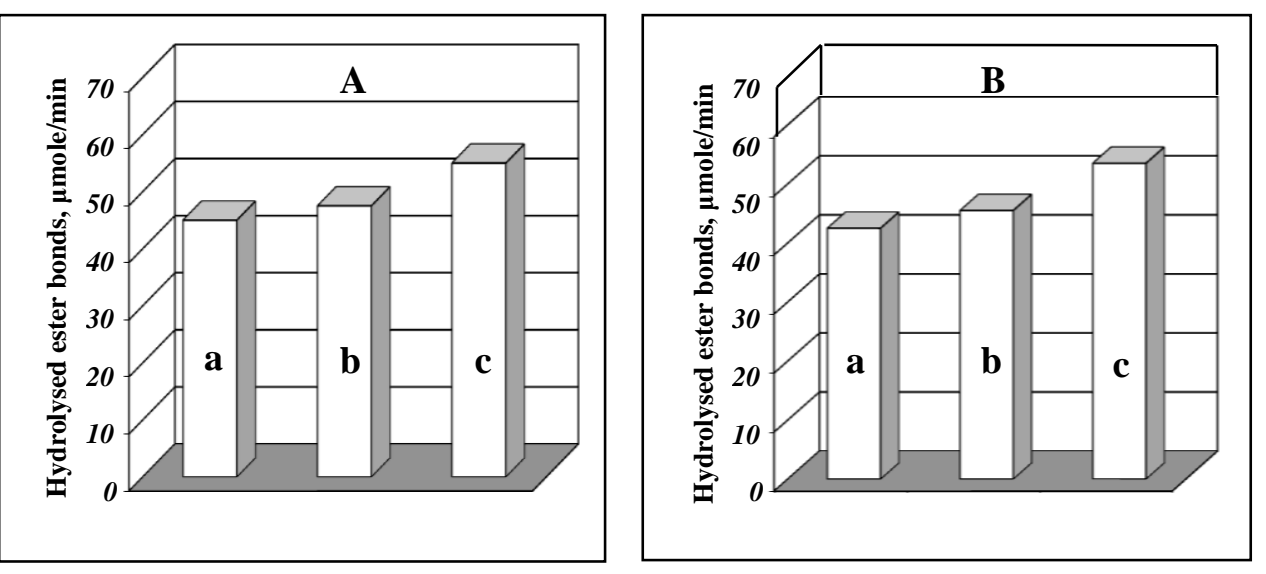

Fig. 6. In vitro biodegradation of co-PEAs films: $\left[\mathrm{BAL}^{\mathrm{V}} / \mathbf{8}\right]_{30 / 70^{-}}-\mathbf{L 1 2}(\mathbf{a}),\left[\mathrm{BAL}^{\mathrm{V}} / \mathbf{8}\right]_{10 / 90}-\mathbf{L 1 2}$ (b) and PEA 8-L12 (c) catalysed by: A - $\alpha$-chymotrypsin and B - lipase. The APT method.
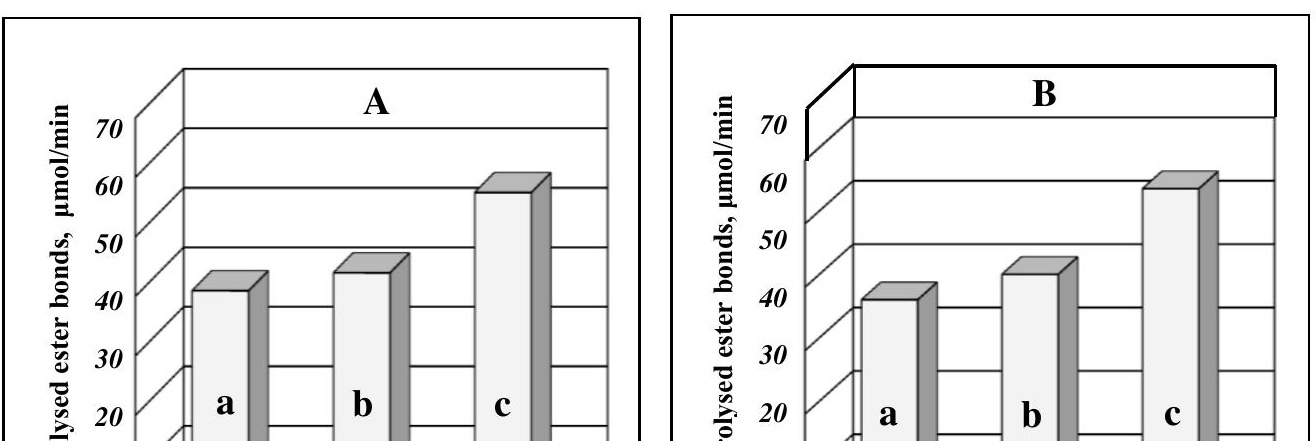


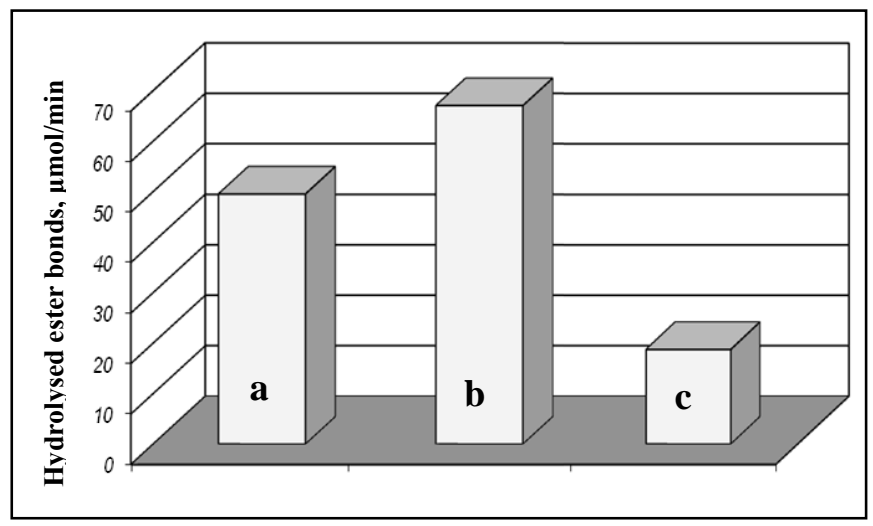

Fig. 8. In vitro degradation homo-PEAs powders: A -hydrolysis of BAL $\mathbf{L}^{\mathbf{v}}-\mathbf{F 6}$ (a) and $\mathbf{B A L} \mathbf{L}^{\mathbf{v}}-\mathbf{L} 6(\mathbf{b})$ catalysed by $\alpha$-chymotrypsin; nonspecific (chemical) hydrolysis of $\mathbf{B A L} \mathbf{L}^{\mathbf{V}}-\mathbf{L 6}$ in $0.1 \mathrm{~N} \mathrm{NaCl}(\mathbf{c})$. The APT method.

The results of the APT express method was confirmed by long term $(140 \mathrm{~h})$ WL method. In Fig. 9 are given the results of in vitro WL kinetics study for two selected samples of the co-PEA $\left[\mathbf{B A L} \mathbf{L}^{\mathrm{v} / 8}\right]_{30 / 70}$ $\mathbf{L 1 2}$ (the curves a) and $\left[\mathbf{B A L}^{\mathrm{V}} / \mathbf{8}\right]_{10 / 90}-\mathbf{L 1 2}$ (the curves b) using $\alpha$-chymotrypsin (A) and lipase (B). For a comparison the degradation curves of the PEA 8-L6 are given as well (the curves c). The WL study confirmed that BAL-based polymers biodegraded slowly as compared with fully aliphatic 8-L6, and the higher was the terephthalic acids content in the polymeric backbones the lower was the biodegradation rate.
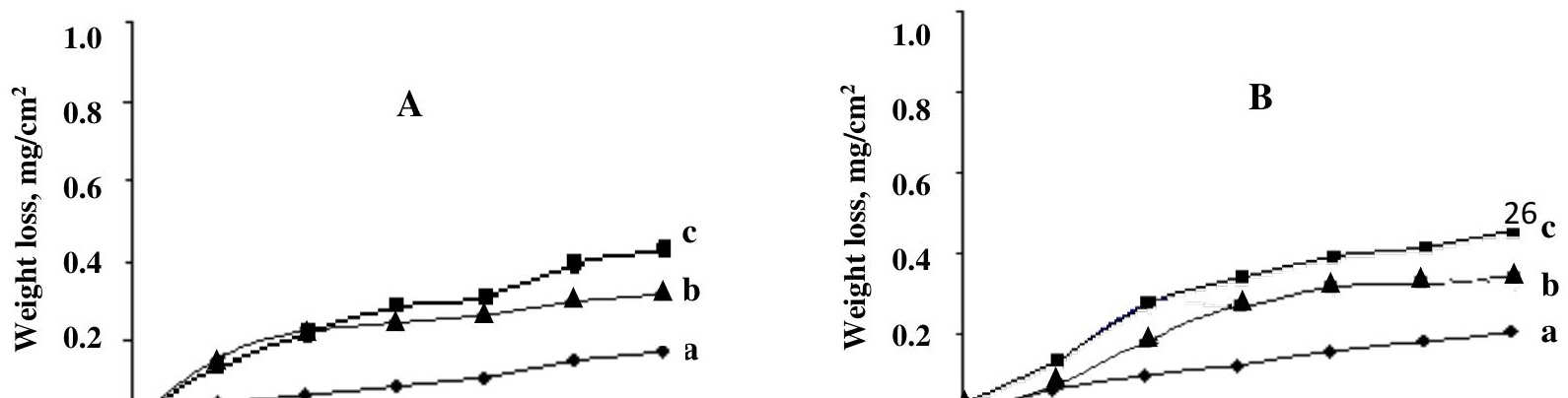
Thus we can conclude that the chain rigidity and strong intermolecular hydrophobic interactions though decrease the biodegradation ability of the BAL-based ester polymers, however, they still retain biodegradability that makes them promising for practical applications. The amorphous structure of the polymers could be a guarantee of their complete degradation in the organism.

\section{Acknowledgment.}

J.P. acknowledges the support from MINECO and FEDER (MAT2015-69547-R), and the Generalitat de Catalunya (2014SGR188). The authors thank Dr. H. Panosyan (Molecule Structure Research Center, National Academy of Sciences of Armenia) for the NMR study.

\section{References}

1. R.Katsarava, N.Kulikova, J.Puiggalí. Amino Acid Based Biodegradable Polymers promising materials for the applications in regenerative medicine. J. J. Regener. Med., 2016, 1(1): 012 .

2. Díaz A, Katsarava R, Puiggalí J. Synthesis, properties and applications of biodegradable polymers derived from diols and dicarboxylic acids: from polyesters to poly(ester amide)s. Int. J. Mol. Sci 2014, 15: 7064-7123.

3. Fonseca AC, Gil MH, Simões PN. Biodegradable poly(ester amide)s - A remarkable opportunity for the biomedical area: Review on the synthesis, characterization and applications. Progr Polym Sci 2014, 39: 1291-1311.

4. Murase SK, Puiggalí J. Poly(Ester Amide)s: Recent Developments on Synthesis and Applications. In Natural and Synthetic Biomedical Polymers. Ch. 8. Edited by Kumbar S, Laurencin C, Deng M, Elsevier Inc; 2014: 145-166. 
5. Katsarava R, Gomurashvili Z. Biodegradable Polymers Composed of Naturally Occurring $\alpha$-Amino Acids. In Handbook of Biodegradable Polymers - Isolation, Synthesis, Characterization and Applications. Ch. 5. Edited by Lendlein A and Sisson A. Wiley-VCH, Verlag GmbH \& Co. KGaA.; 2011: 107-131.

6. Sun H, Meng F, Dias AA, Hendriks M, Feijen J, Zhong Z. $\alpha$-Amino Acid Containing Degradable Polymers as Functional Biomaterials: Rational Design, Synthetic Pathway, and Biomedical Applications. Biomacromolecules, 2011, 12: 1937-1955.

7. Rodriguez-Galan A, Franco L, Puiggalí J. Degradable Polyurethanes and Poly(ester amide)s. In Handbook of Biodegradable Polymers - Isolation, Synthesis, Characterization and Applications. Ch. 5. Edited by Lendlein A and Sisson A. Wiley-VCH, Verlag GmbH \& Co. KGaA.; 2011: 133-154.

8. Rodriguez-Galan A, Franco L, Puiggalí J. Degradable Poly(ester amide)s for Biomedical Applications. Polymers 2011, 3: 65-99.

9. Rodriguez-Galan A, Franco L, Puiggalí J. Biodegradable Poly(ester amide)s: Synthesis and applications. In Biodegradable Polymers: Processing, Degradation. Ch. 4. Edited by Felton GP. NOVA Science Publisher, 2011: 207-272.

10. Katsarava R, Tugushi D. Non-conventional polymers composed of naturally occurring $\alpha$ amino acids". In Unique Properties of Polymers and Composites: Pure and Applied Science Today and Tomorrow. Ch. 7. Volume 1. Edited by Bubnov YuN, Vasnev VA, Askadskii AA, Zaikov GE, NOVA Science Publisher, 2011: 113-131.

11. N.Zavradashvili, G.Jokhadze, M. Gverdtsiteli, G.Otinashvili, N.Kupatadze, Z.Gomurashvili, D. Tugushi, R. Katsarava. Amino Acid Based Epoxy-Poly(Ester Amide)s - a New Class of Functional Biodegradable Polymers: Synthesis and Chemical Transformations. J.Macromol.Sci., Part A, Pure \& Appl. Chem. 50(5), 449-465 (2013).

12. E. Chkhaidze, D. Tugushi, D. Kharadze, Z. Gomurashvili, C.-C. Chu, R. Katsarava. New unsaturated biodegradable poly(ester amide)s composed of fumaric acid, L-leucine and $\alpha, \omega$ alkylene diols. J.Macromol.Sci., Part A, Pure \& Appl. Chem. 48(7), 544-555 (2011).

13. Jokhadze G, Machaidze M, Panosyan H, Chu CC, Katsarava R. Synthesis and Characterization of Functional Elastomeric Poly(ester amide) Co-polymers J. Biomater. Sci. Polym. Ed., 2007, 18: 411-438.

14. K.Guo, C.C.Chu, E.Chkhaidze, R.Katsarava. Synthesis and Characterization of Novel Biodegradable Unsaturated Poly(Ester-Amide)s. J. Polym. Sci. Part A: Polym. Chem. 43, 1463-1477 (2005).

15. I.Legashvili, N.Nepharidze, R.Katsarava, B.Sannigrahi, I.M.Khan. Non-covalent nanoadducts of co-poly(ester amide) and poly(ethylene glycol): preparation, characterization and model drug-release studies. J. Biomater. Sci. Polymer Edn, Vol. 18(6), 673-685 (2007).

16. Nag O.K. Awasthi V.. (2013). Surface Engineering of Liposomes for Stealth Behavior. Pharmaceutics, 5, 542-569.

17. Laurent S., L'H. Yahia. (2013). Protein Corona: Applications and Challenges. Springer Series in Biophysics, V.15. Ch.3. B. Martinac, Ed., 45-63. DOI: 10.1007/978-3-642-37555-2

18. C.S. Cleaver, B.C. Pratt. Polyamides from 2,2'-Bis-[5(4H)-oxazolones]. J. Amer. Chem. Soc., 77, 6, (1955), pp. 1541-1543.

19. C.S. Cleaver, B.C. Pratt. Synthesis of 2,2'-Bis- [5(4H)-oxazolones]. J. Amer. Chem. Soc., 77, 6, (1955), pp. 1544-1546.

20. R.Katsarava, D.Kharadze, L.Kirmelashvili, Heterochain polymers based on amino acids. The oxazolinon method of the synthesis of polyamides containing enzymatically cleavable bonds in the backbones, Acta Polymerica, 36, 1985, 29-38. 
21. R.Katsarava, D.Kharadze, L.Kirmelashvili, N.Medzmariashvili, Ts.Goguadze, G.Tsitlanadze. Polyamides from 2,2'-p-phenylene-bis-oxazolinines and N,N'-bis-trimethylsilylated diamines. Synthesis of polyamides containing tripeptide links in the main chains. Makromol.Chem., 194(1), 143-150 (1993).

22. P.Čefelin, B.Masar̆, D.Kharadze, L.Kirmelashvili, T.Omiadze, M.Burchuladze, L.Edilashvili. Synthesis and in vitro biodegradation study of ther polyamides containing enzymatically cleavable bond in the polymeric backbones. $\mathrm{X}$ International microsymposium on polycondensation. Sunny Beach, Bulgaria, 1985. Proceedings, p. 19.

23. G.Tsitlanadze, T.Kviria, C.C.Chu, R.Katsarava. Biodegradation of amino acid based poly(ester amide)s: in vitro study using potentiometric titration. J Mater Sci.: Mater in Medicine 15, 2004, 185-190.

24. G.Tsitlanadze, M.Machaidze, T.Kviria, N.Djavakhishvili, C.C.Chu, R.Katsarava. Biodegradation of amino acid based poly(ester amide)s: in vitro weight loss and preliminary in vivo studies. J. Biomater. Sci., Polym. Ed. 15 (4), 2004, 1-24.

25. R.Katsarava, V.Beridze, N.Arabuli, D.Kharadze, C.C.Chu, C.Y.Won. Amino acid based bioanalogous polymers. Synthesis and study of regular poly(ester amide)s based on bis $(\alpha-$ amino acid) $\alpha, \omega$-alkylene diesters and aliphatic dicarboxylic acids. J.Polym.Sci.: Part A: Polym.Chem. 37, 1999, 391-407.

26. E. Chkhaidze, D. Tugushi, D. Kharadze, Z. Gomurashvili, C.-C. Chu, R. Katsarava. New unsaturated biodegradable poly(ester amide)s composed of fumaric acid, L-leucine and $\alpha, \omega-$ alkylene diols. J.Macromol.Sci., Part A, Pure \& Appl. Chem. 48, 544-555 (2011).

27. R.Katsarava, D. Kharadze, Study of stability of activated phenyl-esters of carboxylic-acids in polar aprotic media. Zhurnal obshchei khimii (Russia), 61(11), 2413-2418 (1991).

28. C.Hansch, E. Coats, $\alpha$-Chymotrypsin: A case study of substituent constants and regression analysis in enzymic structure - activity relationships. J.Pharm.Sci., 1970, 59, 6, 731-743. 